\section{Investigating Corruption}

Canice Prendergast

\author{
Why incentive contracts and \\ independent investigations \\ may not be the perfect \\ solution to the problem of \\ bureaucratic corruption.
}

The World Bank Development Research Group Public Economics

December 2000 
Policy Resarah Working Paper 2500

\section{Summary findings}

Agency theory has had little to say about the control of bureaucratic corruption, perhaps the greatest agency problem that exists. Prendergast considers the role of incentive contracting in reducing corruption through the use of independent investigations-a common way to monitor corruption.

In simple settings, bureaucratic corruption can be suppressed by rewarding and penalizing bureaucrats, depending on the independent investigators' findings. But Prendergast shows that incentive contracts can change behavior in both undesirable and beneficial ways. He analyzes three possible harmful behavioral responses to investigations.

- Many investigations are (officially) instigated by customer complaints. Bureaucrats could become overinterested in "keeping the customer happy," even when it is not efficient to do so.

- Bureaucrats often have private information on how cases should be handled, information that is hard for investigators to verify. Prendergast shows that investigations can give bureaucrats excessive incentives to "do things by the book," offering decisions that are more likely to be consistent with the opinions of their superiors.

- Bureaucrats sometimes collect bribes to "look the other way"- that is, ignore known transgressions. A solution to this problem might be to offer rewards for bringing cases to light, but a bureaucrat could then waste resources by generating "nuisance cases" simply to receive the bonus.

In each of these cases, harmful responses to investigations and incentives may be costly enough that it would be more efficient simply to pay a flat wage and accept some corruption.

In other words, incentive contracts may not work so well in reducing bureaucratic corruption, because of the variety of dysfunctional responses that investigations may elicit. It may be best to limit investigations to cases where the investigator can find direct evidence of wrongdoing (for example, cash being handed over, or bureaucrats living beyond their means).

This paper-a product of Public Economics, Development Research Group-is part of a larger effort in the group to analyze decentralization and governance in the public sector. Copies of the paper are available free from the World Bank, $1818 \mathrm{H}$ Street NW, Washington, DC 20433. Please contact Hedy Sladovich, room MC2-609, telephone 202-473-7698, fax 202522-1154, email address hsladovich@worldbank.org. Policy Research Working Papers are also posted on the Web at www.worldbank.org/research/workingpapers. The author may be contacted at canice $\alpha$ gsbcxp.uchicago.edu. December 2000. (37 pages)

The Policy Research Working Paper Series disseminates the findings of work in progress to encourage the exchange of ideas about development issues. An objective of the series is to get the findings out quickly, even if the presentations are less than fully polished. The papers carry the names of the authors and should be cited accordingly. The findings, interpretations, and conclusions expressed in this paper are entirely those of the authors. They do not necessarily represent the view of the World Bank, its Executive Directors, or the countries they represent. 


\title{
Investigating Corruption
}

\author{
Canice Prendergast* \\ University of Chicago \& NBER
}

*I am grateful to Gunnar Eskeland, Michael Raith, Tano Santos, participants at USC, the Econometric Society Summer Meetings, LACEA, and especially Kim-Sau Chung for helpful comments. This work was funded by the World Bank, NSF, and the University of Chicago. 



\section{Introduction}

Corruption is undoubtedly a huge agency problem for both developing and developed economies. ${ }^{1}$ Yet if bureaucrats allocating assets for private gain is so costly, what can be done to control its prevalence? In the same way as rewards and penalties can be used to reduce other agency problems, can't appropriate incentive devices be designed to limit corruption? This paper addresses the role of agency theory in controlling the corrupt practices of bureaucrats, and specifically highlights reasons why attempts to reduce its prevalence through the design of rewards and penalties for bureaucrats may not work as well as in other applications.

Agency theory has been used in many fields: ${ }^{2}$ surprisingly, it has had little to say specifically about the control of corruption. Part of the reason for this is that the usual "hidden action" agency model (Holmstrom, 1979) does not correspond well to the environment in which bureaucrats operate. The standard model, which rewards an agent on some observed measure of performance (sales, crop yield, a guilty verdict, etc.), is well suited to understanding contracts offered to executives or salesforce workers, where output measures can be easily ordered from the perspective of the principal. But there are often no good objective measures of bureaucrat performance. For example, consider a bureaucrat who regulates entry to an industry. Should she be paid on the basis of the number of firms that are allowed to enter? Since a corrupt bureaucrat could take bribes from existing firms (who wish to deter efficient entry) or would-be entrants (who wish to encourage inefficient entry), it is unclear how simple output-based contracts can resolve corruption problems. ${ }^{3}$ As a result of these problems, some additional information on the bureaucratic performance is usually required.

In the absence of good measures of performance, a common alternative monitoring device for bureaucrats is through the use of independent investigations. For instance, Klittgard (1994) and Palmier (1985), discuss the importance of independent investigations in developing countries, while the institutions of developed economies are replete with various commissions, tribunals, special in-

\footnotetext{
${ }^{1}$ Recent evidence suggests large costs of corruption both in terms of investment levels and growth rates. For instance, Mauro (1996) illustrates that a one-standard-deviation increase in the "corruption index" increases the investment rate by about 3\% of GNP. See also Bardhan (1997), Alam (1992), Wade (1985) Wei (1997) and RoseAckerman (1997) for consensus on the harmful effects of corruption on efficiency, unlike the more optimistic note taken by Leff (1964).

${ }^{2}$ See Prendergast (1999) and Gibbons and Waldman (1998) for recent surveys

${ }^{3} \mathrm{Or}$ consider a bureaucrat who is supposed to issue passports to qualified applicants. To overcome his incentive to take bribes, the simplest agency perspective would be to reward the agent on the number of passports issued. But should the bureaucrat be rewarded for issuing more passports or fewer? This depends on whether the bureaucrat is taking bribes to issue unwarranted passports or is demanding bribes from customers who legitimately should be given passports (or both). It is difficult to know which is more likely, so that simply rewarding the bureaucrat on the number of passports issued is unlikely to solve the problem.
} 
vestigations and ombudsmen to investigate and resolve suspected cased of bureaucratic malfeasance. This paper is concerned with the use of such independent investigations to control bureaucratic corruption.

What is central to this paper is whether bureaucrats should be rewarded on the outcome of investigations when there is no direct proof of malfeasance. ${ }^{4}$ For example, suppose that a person applies for a passport from a bureaucrat, and is offered that passport. Monitoring of the case by a superior shows that an incorrect decision was made, but no proof exists that cash was handed over to the bureaucrat. Should the bureaucrat be penalized? Perhaps the most important contribution of agency theory is the realization that individuals should be rewarded on observed measures of performance even when there is no proof of malfeasance. Indeed, in the standard agency model, the principal can infer the actions of the agent for sure, yet still compensates on observed noisy outcomes. Such contracts improve ex ante incentives. It is this issue that I address here: should bureaucrats be rewarded on observed outcomes in the absence of proof of malfeasance or should penalties for bureaucrats only be restricted only to cases where there is clear proof? A contribution of this paper is to show how penalties for corruption should sometimes be limited to these cases where there is clear proof of malfeasance. Although such a requirement does not occur in the context of other agency relationships (for example, the value of an executive's compensation package changes for reasons that often have little to do with his efforts), I show that there are particular problems with the implementation of these insights in the context of bureaucrats. It is in this sense that the results of agency theory can help less in the controlling corruption than elsewhere, and points to the restricted use of penalties for bureaucrats to those cases where there is direct proof of malfeasance. Although this conclusion may accord with common practice, it is instructive to note that it constitutes a much more limited use of agency contracts than occur in other settings, where no such proof is needed.

I begin in Section 2 by considering an optimistic benchmark setting, which sets out a positive role for investigations. In the model, there are three actors: a principal, which could be a government agency; an agent, who implements policy; and a customer, which could be a firm seeking a license. In this basic case, the agent observes an imperfect signal of the socially optimal allocation, and carrys out some action. The action affects the customer who receives some private benefit which could differ from social surplus. The customer can bribe the agent to report his preferred allocation. To constrain the agent, she is monitored by a costly sporadic investigation carried out by the principal, who may observe a (possibly imperfect) measure of the true social surplus. I begin by

\footnotetext{
${ }^{4}$ For instance, there is no evidence that cash was given to the official, or that the bureaucrat is clearly living beyond her means.
} 
illustrating the optimality of the use of independent investigations in this setting, where the agent is penalized if the outcome of the investigation differs from the agent's action. Thus, the bureaucrat is penalized in the absence of direct proof of malfeasance. I illustrate in this section that the principal can design a penalty for a risk neutral agent such that the agent always recommends the socially optimal allocation to the principal. ${ }^{5}$ This is the analog to the contributions of traditional agency theory in the context of investigations, and its purpose is as a benchmark against which to analyze other incentives which temper this optimism by addressing realistic extensions of the basic model where the the effectiveness of contracting is limited.

The paper points to three separate reasons for the possible inadvisability of such pay-forperformance contracts. The first concerns the use of complaints as a device to trigger investigations of corruption. In the benchmark model of Section 2, I assume that the principal chooses when to monitor the agent's performance, and is more likely to do so when he believes an error has been made. Such targeting is done because monitoring is costly, and so the principal wants to intervene only when he thinks something needs to be corrected. ${ }^{6}$ A common source of such information is a complaint by a customer. In order to economize on the principal's time, and to properly focus investigations on those cases where errors are likely to be made, customer complaints tend (optimally) to be used to launch investigations. The use of complaints as a means of focusing monitoring is ubiquitous in both the private and public sectors, yet has been little studied in the literature. The role of complaints is simply modeled in Section 3.

\footnotetext{
${ }^{5}$ The literature on agency theary has pointed to two problems that arise when rewarding agents on noisy performance measures. First, the noisiness of the relationship between observed measures and the agent's performance imposes risk on the agent, which is refiected in higher compensation costs. From this perspective, the tradeoff of risk and incentives constrains the ability of a principal to control malfeasance. The agency literature on bureaucratic corruption has largely addressed this tradeoff, using risk averse or liquidity constrained agents, where the use of pay-for-performance per se on wages is costly. (A common approach taken in the literature is via efficiency wage models.) See Besley and McLaren (1993), Flatters and MacLeod (1995), Basu et al. (1992), Mookherjee and Png (1995), Banerjee (1997) and Eskeland and Thiele (1999) for examples of this approach. I do not deal with this by now standard cost of agency contracting for twa reasons. First, I wish to illustrate some other influences at play when independent investigations are used to monitor agents. Second, there is little empirical evidence that risk costs truly constrain agency contracts. In other work (Prendergast, 2000a, 2000b), I show that the empirical work on this topic seem to point more towards a positive correlation between measures of uncertainty and the strength of incentives, rather than the negative relationship predicted by the theory. Instead, I focus on the second cost of incentive pay, namely, multitasking, where agents carry out dysfunctional actions that are in her own interest rather than those that maximize surplus (Holmstrom and Milgrom, 1992). In this paper, the particular forms of dysfunctional behavioral responses arise from the use of investigations.

${ }^{6}$ The costliness of monitoring, in itself, it not necessarily a problem, as noted in Becker (1968). In Becker's setting, there is a tradeoff between larger penalties and higher probabilities of monitoring when an agent chooses whether to "cheat". Since monitoring is costly, the efficient solution is to monitor infrequently and offer large penalties when the agent is found to be malfeasant. Thus, once rewards are unbounded, the first best allocation can be easily attained, even when the cost of monitoring is high. But this ignores one important reason for monitoring; namely, that it is often used to correct honest mistakes in addition to eliminating moral hazard, as arises here. For instance, the primary reason for an appeals process in the judicial system is to overturn wrongful convictions, not simply to monitor judges. As a result, it is not efficient in this model to monitor with vanishingly low probability.
} 
What matters for complaints mechanisms as a monitoring device is how well they identify mistakes or malfeasance. I begin by illustrating the importance of complaints in a setting without corruption. In this case, complaints improve social surplus because they can truly identify (honest) errors, and so cause a higher likelihood of an investigation than when no complaint is registered. As a result, it is hardly surprising that in many settings, complaints trigger monitoring and increase surplus. But investigations are also used to penalize bureaucrats for malfeasance, and bureaucrats may wish to avoid investigations by minimizing the likelihood of a complaint being made. But what better way to reduce the likelihood of a complaint than by giving the customer what he wants? I show that the desire to avoid a investigation induced by complaints can cause the agent to act corruptly by "keeping the customer happy" even when it is not efficient to do so. Furthermore, corruption can increase when the penalty for being found guilty rises. The intuition is simple and intuitive: as the penalty for corruption rises, agents become increasingly afraid of an investigation and become more likely to acquiesce to the desires of the consumer. Thus, the (optimal) reliance on customer complaints, and its effect on bureaucrats' actions becomes the first reason why payfor-performance contracts for bureaucrats can be counterproductive.

Even in the absence of costly monitoring, the use of investigations can backfire for a second reason described in Section 4. Here the problem is that the agent responds to the contract to constrain corruption by making inefficient information investment choices. To place this in some context, note that bureaucrats are often offered discretion because they have more specialized knowledge than the principal. For example, industry experts who are charged with regulation often know more about the industry than those who oversee them. Suppose further that certain types of information are more difficult to verify than others. For instance, a bureaucrat may know that certain bidders for a contract produce higher quality output than others, but it may be difficult to verify such differences to a superior. The problem with offering compensation contracts based on independent investigations is that the bureaucrat may ignore such efficient non-verifiable information when making recommendations, despite its social optimality, and will instead do things "by the book". She does this by emphasising more easily quantified data (such as bids), she is more likely to come to the same conclusion as an independent investigation. To phrase the problem another way, the reason that the bureaucrat is given discretion over allocating resources is because she has some useful private information. Yet monitoring her over her decisions means that she no longer uses that discretion. In Section 4 I show how the optimal response to this problem may be to avoid incentive contracts and allow corruption. This arises when a well-informed but corrupt bureaucrat dominates an honest but ill-informed one.

Section 5 illustrates a third problem with pay-for-performance contracts. In many settings, 
bureaucrats are required not only to make decisions on known cases, but are also charged with identifying relevant cases for investigation. For example, consider a bureaucrat who is in charge of enforcing the law on pollution control. Such bureaucrats not only make recommendations on cases which have come to light to superiors, but also spend considerable time identifying potential violations, which are otherwise unlikely to come to the attention of the superior. When bureaucrats identify relevant cases in addition to making decisions on known cases, an additional incentive arises, where bureaucrats take bribes to "look the other way". In itself; this problem has a solution, where the bureaucrat is offered a return for bringing cases to light. But this "solution" causes an additional problem in that it generates an incentive to produce "nuisance cases", which are generated simply to receive the bonus for bringing cases to light. In Section $5 \mathrm{I}$ illustrate that the contract required to induce agents to bring a case to the principal may need a reward so large that it induces the agent to uncover such socially suboptimal ("nuisance") cases, potentially wasting resources in the process. I show that if the propensity to generate such nuisance cases is large enough, the principal should once again restrict the use of pay-for-performance contracts, and allow the agent the discretion to be corrupt by taking bribes to ignore cases. Again, allowing corruption may be the optimal response to the limitations of the ability to monitor bureaucratic malfeasance.

Before discussing the details of the model, it is important to note at the outset that the paper is concerned with cases the objective of the principal is to maximize social surplus and the constraining factor is the willingness of bureaucrats to take bribes to do otherwise. As such, the paper is not meant to understand why, say, Zaire is generally considered more corrupt than Norway. That issue is most likely better understood by considering their political processes and how the objectives of their governments vary. Instead, this paper is more limited in its range, and is concerned with understanding why a principal with the objective of maximizing surplus is limited in his ability to do so by the actions of his bureaucrats.

I begin in Section 2 by setting up the basic model and showing how, in a simple setting, the firm can design punishments for perceived infractions such that the agent acts honestly. The objective of the subsequent sections is to identify caveats to this conclusion, even with risk neutral agents. First, in Section $3 \mathrm{I}$ illustrate how the desire to avoid complaints can cause corruption by bureaucrats, and most importantly, how the use of pay-for-performance contracts can exacerbate problems of corruption. Second, Section 4 shows how the use of contracts that reward people for perceived corruption can induce the bureaucrat to do things "by the book", resulting in such a reduction in the use of discretion that the allocation may be better if no contracts were offered. Finally, Section 5 considers the incentive of agents to ignore cases, and shows how the solution to this problem may result in incentives to generate "nuisance cases". Once again, the optimal policy may be to allow 
corruption. I conclude with a brief discussion, where I argue that a sensible way of monitoring bureaucrats may be to restrict penalties only to those cases where malfeasance itself can be proved.

\section{The Basic Model}

A principal must decide on the allocation of an asset $x$, which can take on three possible values, (i) an increase from its current value $(x=1)$, (ii) no change $(x=0)$, or (iii) a decrease from its current level $(x=-1)$. The social surplus from the allocation depends on a parameter $\alpha$ and is given by

$$
S(x ; \alpha)= \begin{cases}1 & \text { if } x=\alpha \\ 0 & \text { otherwise }\end{cases}
$$

Thus social surplus is positive only if $x$ is properly matched to the underlying environment, $\alpha$. The true value of $\alpha$ is unknown and can take three values $\alpha=1, \alpha=0$, or $\alpha=-1$. with equal probability. The agent collects information on $\alpha$. In particular, she observes $\alpha_{a}$ which is correct with probability $q \geq \frac{1}{3}$, where with probability $\frac{1-q}{2} \leq \frac{1}{3}$, she observes each $\alpha_{a} \neq \alpha$. Thus the agent is imperfectly informed.

Investigations are typically sporadic, because they are costly, and are triggered by some suspicion of malfeasance. To model a role for investigations, I assume that the principal chooses a probability of observing a signal on the true state of nature, $\alpha$, at some cost. Specifically, the principal chooses a probability $\rho$ with which he observes a signal $\alpha_{p}$, at a cost $\kappa(\rho)$, where $\kappa^{\prime}(\rho)>0, \kappa^{\prime \prime}(\rho)>0, \kappa^{\prime}(0)=$ 0 , and $\kappa^{\prime}(1) \geq 1$. In this section and in the next, I assume that the signal received by the principal is perfect, so that $\alpha_{p}=\alpha$. (This assumption is merely to simplify algebra.) I assume that the act of observing $\alpha_{p}$ is not contractible, nor is the probability of monitoring. Because monitoring is not contractible, the principal monitors in a subgame perfect fashion. ${ }^{7}$

For future reference, let $\rho^{*}(z)$ be the ex post optimal monitoring intensity if the principal believes that the allocation suggested by the agent is incorrect with probability $z$. This is given by

$$
\rho^{*}(z)=\kappa^{\prime-1}(z)
$$

In what follows, the principal will use all available information to compute $z$ and tailor monitoring

\footnotetext{
${ }^{7}$ This rules out strategies where the principal, for example, always monitors or monitors independent of available credible information.
} 
propensities accordingly.

There is another individual, a customer, whose preferences may differ from those of the principal, and can offer the agent a bribe to report something other than her true observation. In particular, the customer's preferences (possibly) diverge from the social optimum by a parameter $\beta$ where as with $\alpha$, I assume that $\beta$ has a prior uniformly distributed over $\{1,0,-1\}$. The customer receives private benefits which consist of the $x$ closest to $\alpha+\beta$. More specifically, let $\tilde{\alpha}=\alpha+\beta$ for $|\alpha+\beta| \leq 1$ and $\alpha$ otherwise. Then the customer's private benefits are

$$
B(x ; \alpha, \beta)= \begin{cases}1 & \text { if } x=\tilde{\alpha} \\ 0 & \text { otherwise }\end{cases}
$$

Therefore, the agent has preferences which are possibly different from the social optimum. The agent and the customer both observe the values of $\alpha_{a}$ and $\beta$, but the principal observes neither. (The importance of this uncertainty is discussed below.) Thus, the strength of the customer's preferences for non-surplus enhancing outcomes is a potential source of uncertainty to the principal. Note also that in some circumstances, the social and private optima coincide. ${ }^{8}$

As the agent and the customer share a common information set, I assume that they can bargain efficiently over the allocation offered by the agent. Specifically, they can write enforceable contracts specifying a transfer between the customer and the agent for a given allocation by the agent. Since bargaining is efficient, the agent will make an allocation that maximizes their joint surplus, which is bargained over in some unmodeled fashion. Direct proof of these transactions is not available to the principal. The customer has some asset with which to bribe the agent, where a $\$ 1$ transfer to the customer has value $\$ v$ to the agent. Unless otherwise stated, I assume that $v=1$, so that we are considering monetary bribes, though $\mathrm{I}$ also consider the case where $v=0$ as a (no collusion) benchmark where appropriate.

The objective of the principal is to maximize ex ante social surplus, $E S\left(x ; \alpha_{r}, \alpha_{p}\right)$, at all points in time, where $\alpha_{r}$ is the allocation made by the agent, and $\alpha_{p}$ is the observation made by the principal, if one is received. If indifferent over social surplus allocations, the principal minimizes payments to the agent. ${ }^{9}$ In other words, the principal makes a decision to monitor based on

\footnotetext{
${ }^{8}$ Note that the maximum private surplus is identical to the social surplus that arises for the principal. This might suggest an alternative mechanism, where the principal sells the right to allocate the asset to the agent, who collects the rents from the customer, yielding (possibly) efficient outcomes. But note that $I$ have assumed that the principal only cares about social surplus per se rather than its monetized equivalent. Thus the principal is not willing to accept cash as an alternative to the allocation itself. This assumption is purely for simplicity. An alternative which will suffice is to make the cost of social misallocation large relative to the private benefits. So, for example, identical results would arise if the principal valued money but private benefits were of maximum value $\delta<<1$.

${ }^{9}$ This assumption greatly simplifes the analysis, because it allows me to ignore the monetary implications of the
} 
whether monitoring will increase social surplus or not. ${ }^{10}$ This agent maximizes expected monetary payments. No contracts are offered to the customer. ${ }^{11}$

The timing is as follows. First, the firm offers the worker a contract $w\left(\alpha_{r}, \alpha_{p}\right)$, where $\alpha_{p}$ is the observation made by the principal, if one is received. This contract must satisfy the agent's participation constraint, where his outside options are normalized to zero and the contract signed before any random variables are observed. The agent and customer then simultaneously observe $\alpha_{a}$ and $\beta$ and negotiate over an allocation $\alpha_{r}$ made by the agent, where the allocation maximizes the joint surplus of the two parties. Following the report, the principal then chooses a probability $\rho$ of observing $\alpha_{p}$. If he receives information on $\alpha$ which is different to that of the agent's recommendation, he changes the allocation to $\alpha_{p}$ as this increases expected surplus. If $\alpha_{p}$ is not observed, the allocation remains unchanged at $\alpha_{r}{ }^{12}$ The agent is then paid.

\subsection{The Benchmark with No Corruption}

It is useful to begin with the outcome that arises when no corruption occurs, where $v=0$. In this case, the agent is incorrect with probability $1-q$ and the principal sets $\rho$ by maximizing $(1-q) \rho-\kappa(\rho)$, so the principal monitors with probability $\rho^{*}(1-q)=\kappa^{\prime-1}(1-q)$. As there is no corruption, the agent can be rewarded by a salary equal to his outside option. In that case the surplus from the relationship is

$$
S^{n}=q+(1-q) \rho^{*}(1-q)-\kappa\left(\rho^{*}(1-q)\right)
$$

compensation scheme; while the principal values money, he has lexicographic preferences for improving the allocation. Formally, I assume that there is an infinite marginal rate of substitution between money and the asset being allocated, which allows me to ignore the monetary implications of contracts on the surplus created. See Banerjee (1997) for a similar assumption.

${ }^{10}$ What this rules out is using the compensation plan to make monitoring credible, as in Khalil (1997), Jost (1991), Mitusch (1998), and Eskeland and Thiele (1999), where the principal uses contracts as a commitment device. More specifically, consider a contract where an agent is fined if he is found to have made an error, and where the principal keeps the fine. By choosing the penalty large enough, the principal can be given incentives to monitor in ways different to the ex post optimal rule. While obviously theoretically correct, I ignore this possibility as it has little empirical relevance. In reality, either the punishments meted out to those who are found guilty of corruption are typically non-monetary, for example through prison sentences, or the principal does not benefit from the penalty, as when the bureaucrat is fired and replaced by someone else. As a result, it seems simply implausible that the principal can commit himself through the possibility of a large monetary payoff in the event of uncovering some corruption.

${ }^{11}$ There are two justifications for this assumption. First, from a formal perspective it is unlikely that consumers are sufficiently well informed of the parameters of the model to understand the likely outcome of any contract on their welfare. For instance, they are unlikely to know how likely it is that a commission comes to a particular conclusion. The second justification is simply a legal one: it is not legal in many setting to design payment contracts for some public services, such a citizenship. This assumption rules out mechanisms where the agent's report is compared to one made by the customer, where each is penalized if they do not make the same report. These mechanisms can sometimes result in (usually non-unique) equilibria where truth-telling arises.

${ }^{12}$ At the point where the allocation is made, the principal never strictly gains from changing the allocation from $\alpha_{r}$ if $\alpha_{p}$ is not observed. 
Note that the monitoring intensity is independent of the action by the agent, as the action itself is uninformative of errors.

\subsection{The Outcome with Corruption but No Incentive Contract}

Initially consider the case where $v=1$ but the agent is offered a salary, $w\left(\alpha_{r}, \alpha_{p}\right)=w_{0}$, for all $\alpha_{r}$ and $\alpha_{p}$. This illustrates the extent of the agency problem. By natural extension to the definition above, let $\tilde{\alpha}_{a}=\alpha_{a}+\beta$ for $\left|\alpha_{a}+\beta\right| \leq 1$ and $\alpha_{a}$ otherwise. This allocation maximizes the agent's and customer's joint surplus with no incentive payments, based on their knowledge when reporting. As there is no penalty for corruption, she allocates $\alpha_{r}=\tilde{\alpha}_{a}$.

Remember that the principal can condition his choice of monitoring on all observed information. In this case, that means that the principal can condition this choice on the agent's allocation. With some abuse of notation, let $\rho^{*}\left(\alpha_{r}\right)$ be the monitoring propensity for an action $\alpha_{r}$. Lemma 1 illustrates the surplus from offering no incentive contract, whose proof is in the appendix.

Lemma 1 Assume that $w\left(\alpha_{r}, \alpha_{p}\right)=w_{0}$. The agent implements $\tilde{\alpha}_{a}$ and the surplus is

$$
\hat{S}=\sum_{j=-1}^{1} \frac{1}{3}\left(\left[1-\rho^{*}(j)\right]\left[1-\kappa^{\prime}\left(\rho^{*}(j)\right)\right]+\rho^{*}(j)-\kappa\left(\rho^{*}(j)\right)\right)<S^{n}
$$

where $\rho^{*}(0)=\kappa^{\prime-1}\left(\frac{2}{3}\right)$ and $\rho^{*}(1)=\rho^{*}(-1)=\kappa^{\prime-1}\left(\frac{5-3 q}{6}\right) \leq \rho^{*}(0)$.

Not surprisingly, corruption reduces social surplus, through the misallocation of resources. This misallocation occurs because of the nine $\left(\alpha_{a}, \beta\right)$ states, four of them involve a divergence between the social and private optimum. ${ }^{13}$

\footnotetext{
${ }^{13}$ Consider the difference between the socially and privately optimal allocations: this determines the monitoring propensities. First, when $\beta=0$ (which occurs with probability $\frac{1}{3}$ ), there is no distortion as the social and private optima coincide. Similarly, there is no distortion in the case where $\alpha_{a}=\beta$, since the optimal social and private action is to choose $x=\alpha_{a}$. These states occur with additional probability $\frac{2}{9}$. Therefore, problems arise only in the states where the social and private optima diverge, which are the following $\left(\alpha_{a}, \beta\right)$ states: $(1,-1),(0,-1),(-1,1)$, and $(0,1)$. Thus, corruption can either take the form of implementing "no change" when some should occur, or imposing change when "no change" is optimal. These states occur with probability $\frac{4}{9}$. The distortions below are those caused in these four states where private and social optima do not coincide. In particular, there is misallocation of resources in each of the four states where $\tilde{\alpha}_{a} \neq \alpha_{a}$ as she allocates incorrectly. The incorrect actions of the agent can be partly undone by sometimes relying on the principal's information, and by tailoring monitoring to those states where malfeasance has occurred. Note from above that the agent has an incentive to act corruptly in states $(1,-1),(0,-1),(-1,1)$, and $(0,1)$ : in states $(1,-1)$ and $(-1,1)$, this implies a recommendation of $x=0$, while the other two recommendations are made in one of the remaining states. This means that the recommendation $x=0$ is the most suspicious state and so the principal will monitor more extensively when $\alpha_{r}=0$ than in the other two states. See Braun and Di Tella (2000) for other work emphasizing the endogeneity of monitoring propensities for controlling corruption.
} 


\subsection{Inducing Truth-Telling}

There are two conceivable ways of inducing the agent to report truthfully. First, the agent can be investigated and rewarded relative to the outcome of the principal's findings. This is the approach taken throughout the paper. However, there is a second approach which is to reward the agent based on his report only, and to avoid compensating based on the principal's information. Thus, for example, a bureaucrat could be offered a bonus every time a customer is denied a license. The primary mechanism that has been suggested in the context of bureaucrats has been proposed by Tirole $(1986,1992)$. This mechanism proposes a reward to the bureaucrat whenever he offers an allocation which harms the consumer. ${ }^{14}$ Yet, to my knowledge, such contracts for bureaucrats are rare, and instead other information is usually necessary for the penalizing of bureaucrats.

There are many ways to formally model the limited role of contracts based only on the allocation of the agent. I do so here by assuming that the allocation carries little information about corruption. This is the reason why the principal is assumed to be uncertain about the joint surplus of the agent and customer. ${ }^{15}$ Note that the distribution of the social optimum is identical to the private optimum: both are uniformly distributed. ${ }^{16}$ Lemma 2, whose proof is in the Appendix, illustrates the limited value of these contracts in this setting.

Lemma 2 Assume that the agent randomizes with equal probability over allocations about which she is indifferent. The maximum surplus that can be attained by a contract $w\left(\alpha_{r}, \alpha_{p}\right)=w\left(\alpha_{r}\right)$ is

\footnotetext{
${ }^{14}$ To see this, consider the following example, which follows from Tirole (1992). Suppose that a bureaucrat reports on the costs of production of some firm doing work for a government agency. For simplicity, assume that the costs of the firm are $\$ 1$ or $\$ 2$, and the agent has private information on the true level of costs. The government pays the firm its costs. The opportunity for corruption arises because the firm benefits by the bureaucrat reporting costs to be $\$ 2$ rather than $\$ 1$. The firm will be willing to give the bureaucrat up to $\$ 1$ if he will report costs of $\$ 2$. The principal responds by offering the bureaucrat a reward of $\$ 1$ for reporting costs of $\$ 1$ rather than $\$ 2$. In this way, the bureaucrat is indifferent between reporting that costs are $\$ 2$ and honestly reporting that costs are $\$ 1$. Thus, contracts can be designed to eliminate corruption when the wage benefit the bureaucrat gets from harming the consumer is at least as great as the bribe that the consumer would offer for a better recommendation.

${ }^{15}$ There are many reasons for this uncertainty. First, the principal may not know who has access to bribe the official (the entrant or the incumbent firm in the regulator example above), so it is unclear how private and social benefits diverge. Second, the bureaucrat may be able to accept bribes to offer more of an asset than is optimal, or may demand bribes for legitimate use of an asset, so again it is hard to tell how allocations are reflective of corruption. Third, some bureaucrats may be more susceptible to bribes than others, so that the private costs of accepting bribes may be the source of uncertainty. Finally, it may be known which direction a customer may wish to bribe, but not the strength of his preferences. For example, it may be well known that incumbent firms will pay to restrict entry, but harder to know how much they will pay. (The paper can be easily extended to deal with the case where the private benefits have a mean which is not zero, as would be required for this case.) The simple model above is meant to capture such uncertainty; the model could be adapted to deal with any of these specifics, but is left abstract in the interests of simplicity. Its formal role is nothing more than to offer a reason why contracts based only on the recommendation of the bureaucrat are of limited value.

${ }^{16}$ This assumption is stark, and limits the ability of the principal to control corruption. In particular, subject to an indifference condition, this assumption implies that there is no role for such contracts to eliminate corruption, but would easily generalize to cases where these contracts only partially solve the corruption problem: all that is necessary is that there is a residual role for investigations.
} 
no higher than $\hat{S}$.

Given the limited use of such "output-based" contracts, ${ }^{17}$ I now consider the role of investigations as a means of constraining corruption. Investigations take the form of a contract where the agent is penalized if an investigation occurs and the agent is found to have made an allocation different from the finding of the investigation. In particular, I consider contracts of the form

$$
w=w_{0}-\Delta I
$$

where

$$
I= \begin{cases}1 & \text { if the principal observes } \alpha_{p} \text { and } \alpha_{r} \neq \alpha_{p} \\ 0 & \text { otherwise }\end{cases}
$$

Thus, the paper proposes a very simple mechanism based on the use of investigations. ${ }^{18}$ Namely, the agent is penalized only if the principal receives information that differs from the allocation proposed by the agent. ${ }^{19}$ Note also that bureaucrats have nothing to gain from being investigated: this is important in what follows. The salary $w_{0}$ is chosen so as to satisfy the worker's participation constraint, and is of little importance here, so it is ignored in what follows.

Not surprisingly, in this simple setting, investigations can be used to eliminate malfeasance, by choosing $\Delta$ large enough. Thus, the insight that agents should be rewarded and penalized on observed measures of performance even in the absence of proof of malfeasance continues to hold in this model. As such, this outcome is the natural analog to that of the standard agency model in the context of investigations. The (benchmark) result of this section is summarized in Proposition 1.

Proposition 1 In the basic model, the agent can be induced to report the state truthfully by offering $\Delta \geq \Delta^{*}=\frac{1-\kappa^{\prime}-1(1-q)}{\kappa^{\prime-1}(1-q)}$.

\footnotetext{
${ }^{17}$ This Lemma is meant to illustrate how investigations may be necessary to make progress in solving corruption problems. It does so by setting up a model where the allocation itself is largely uninformative of corruption, as the distribution of $\alpha_{a}$ is identical to the distribution of $\tilde{\alpha}_{a}$. In cases where there is information on corruption from the allocation, clearly there is a role for output based contracts, and indeed even in this case, in some circumstances different indifference rules can possibly make some progress. All that Lemma 1 is meant to do is allow me to consider a model where output-based contracts do little, so that I can concentrate on investigations.

${ }^{18}$ See Chung (1999) for an analysis of other mechanism in this context, and their inability to achieve first best outcomes.

${ }^{19}$ Formally, I assume that the act of observing $\alpha_{p}$ is not contractible: only if the principal chooses to report $\alpha_{p}$ can the agent be penalized. As a result, the principal will do so only if he gains from doing so, namely, when $\alpha_{r} \neq \alpha_{p}$ This assumption rules out the use of credible bonuses that would be paid if the investigation concurred with the findings of the principal.
} 
Hence, so long as the principal monitors with positive probability (as occurs when $q<1$ ), a contract can be designed to induce efficient actions, but where the required sensitivity of the performance contract $\left(\Delta^{*}\right)$ is decreasing in the frequency of monitoring, as is standard in agency settings with risk neutral agents. ${ }^{20}$ The purpose of the following section is to illustrate why this optimistic conclusion may be unfounded in more complex settings, where in some cases the principal will not design the contract to induce the agent to report truthfully; instead, the agent will sometimes be corrupt in equilibrium. Note, however, in cases where the agent is corrupt, there are positive values of $\Delta$ that induce the same behavior as when $\Delta=0$. For simplicity, since the allocations are unchanged for all such values of $\Delta, I$ choose $\Delta=0$ throughout the paper as the "no-incentives" contract.

\section{Complaints}

In the model above, the principal only investigates based on the allocation made by the agent. But in many cases this is inefficient, since the value of the principal's time is high, and he will often look for other information that suggests that an error has been made. Perhaps the most important source of information on errors and malfeasance comes from customers, who can express their unhappiness about an outcome by making a complaint. As mentioned in the introduction, the use of complaints in corruption settings is ubiquitous and serves to distinguish routine cases from those where there is a need to intervene. For example, one of the primary responsibilities of the Central Vigilence Committee in India (which investigates corruption) is to "deal with complaints relating to corruption" (Palmier, 1985, p.52). ${ }^{21}$

I begin this section by showing the value of complaints in the absence of corruption. However, although complaints can help focus monitoring, using them to restrict corruption can easily be counterproductive. This is because higher penalties for perceived corruption can induce more corruption rather than less, as occurred in the basic model above. The intuition for this is simple. The agent has information both on the socially optimal allocation and on the allocation preferred by the customer. She then carries out an action based on her incentives. Her choice is based on

\footnotetext{
${ }^{20}$ It should be stressed that this benchmark contract is not the only contract that can induce truth-telling, but is a simple natural mechanism; namely, an independent body makes an investigation and penalizes the agent only if it reaches conclusions different from those recommended by the agent.

${ }^{21}$ Part of the reason why complaints are relied on so much is that there is a failure of government departments to self-monitor corruption by their own agents. For example, Palmier notes that "there have been very few cases where requests have been made by the ministries or departments to the Special Police Establishment to make inquiries into allegations of bribery or corruption against their staff" (p.66); instead "the principal source of information for Vigilence Officers is complaints" (p.71). In 1977-78, only $2 \%$ of corruption charges arose from departmental investigations while $38 \%$ of investigations came as a direct response to complaints.
} 
both (i) the likelihood of an investigation and (ii) on the outcome of that investigation. The central point of this section is that these two incentives work in opposite directions; as in the basic model, there is an incentive for truth telling conditional on being investigated. However, there is also an incentive to reduce the probability of being investigated. This is done by avoiding complaints and what better way to avoid a complaint than by giving the customer what he is likely to want, even when this is not socially optimal? Therefore, the means of correcting mistakes can cause corruption to occur, through the medium of reduced complaints.

To analyze the effects of complaints on agent and principal behavior, I add another stage to the game, where after the agent has made his report to the principal, but before the principal's decision to monitor, the customer privately observes a signal $\alpha_{c}$ on the true value of $\alpha$. It is assumed that this signal is correct with probability $s \geq \frac{1}{3}$. Upon receiving this signal, the customer sends a non-contractible message $m \in\{n, c\}$, where the message $n$ means that no complaint is made and message $c$ implies that a complaint has been made. The customer and agent cannot contract over the complaint message. ${ }^{22}$

The agent is rewarded by a contract as in (6), where she is penalized if she (i) is investigated and (ii) is found to have made the wrong decision, with the only choice being over $\Delta$. The use of this contract is important, as it implies that the agent wants to avoid investigations. ${ }^{23}$ Furthermore, the compensation scheme cannot be directly conditioned on whether the customer complains. ${ }^{24}$ Thus, the only effect of a complaint on the agent's welfare is through the likelihood of being monitored.

In the previous section, the principal chose a monitoring probability $\rho$ as a function of the allocation made by the agent. Here, the principal can condition this choice not only on the allocation but also on the consumer's message, $\rho\left(\alpha_{r}, m\right)$. He then (possibly) changes the allocation if he observes $\alpha_{p}$; otherwise, he chooses $x=\alpha_{r}{ }^{25}$

\footnotetext{
${ }^{22}$ The interpretation of this is that there is some delay before the customer receives information on $\alpha$ by which time the relationship between the agent and the customer is terminated. At that moment in time, the customer makes the static optimal choice of whether to complain.

${ }^{23} \mathrm{An}$ alternative would be to offer the agent a bonus for being investigated. This is not credible here because monitoring is not contractible, so that the states "no observation of $\alpha_{p}$ " and "observing $\alpha_{p}$ and $\alpha_{p}=\alpha_{r}$ " are observationally equivalent if the principal claims not to have observed $\alpha_{p}$. Consequently, the principal cannot credibly offer a bonus to the agent if he investigates and finds that $\alpha_{p}=\alpha_{r}$; he will simply renege by claiming not to have observed $\alpha_{p}$. As a result, the only credible way of monitoring the agent is with a penalty conditional on investigation.

${ }^{24}$ To give an example, suppose that a professor receives an anonymous note accusing another student of cheating on an exam. This note in itself is generally not enough to penalize the accused student, but may result in more monitoring of that student's performance.

${ }^{25}$ This is assumed for two reasons. First, principals themselves may be required to provide verifiable evidence to avoid being corrupt themselves. Second, although complaints can be a useful source of information, the principal should be aware of the incentive for customers to make "nuisance complaints", where the very act of complaining could affect the beliefs of the principal and hence lead to the allocation being changed. This danger of nuisance complaints is non-trivial; Palmier, 1985, notes that in addition to dealing with legitimate complaints by customers, the Vigilence Commission in India takes "actions against people making false complaints" (p.52). To avoid dealing
} 
The analytics of the problem can be most easily seen where $s=1$, so that the customer observes the true state of the world perfectly. I am primarily interested in the case where complaints are credible, where the customer complains if an error has been made, and the principal can correct it to something that the customer prefers. This implies that the customer complains if (i) the allocation he has been offered is not his preferred one $\left(\alpha_{r} \neq \tilde{\alpha}\right)$ and (ii) the privately optimal allocation is $\alpha$. However, as a modeling device, I illustrate the value of complaints mechanisms by comparing this equilibrium to one where complaints are simply babble, i.e., the principal believes that the customer's messages are uninformative.

\subsection{A Role for Complaints: $v=0$}

To illustrate the importance of complaints, I initially consider a case where there is no corruption, by assuming that $v=0$, so that the customer and the agent cannot trade with each other. This "nocollusion" setting illustrates the importance of complaints as a mechanism for identifying errors. To show the importance of complaints, compare the two equilibria of the game where there is no collusion between the agents; (i) where the complaint message is "babble", and (ii) where complaints are most revealing.

When complaints carry no information, the outcome is as in (4), with surplus $S^{n}$ and the principal monitors with equal probability $\rho^{*}(1-q)$ in all states. This can be improved upon by tailoring monitoring based on complaints, as I now illustrate.

\subsubsection{Efficient Complaints}

The customer is assumed to complain only if it benefits him and complaints are credible. This implies that the customer complains when (i) the agent made the wrong decision $\left(\alpha_{r} \neq \tilde{\alpha}\right)$, and (ii) the customer benefits from a change to the correct one $(\tilde{\alpha}=\alpha) \cdot{ }^{26}$ What is important here is how the incentive to monitor depends on the complaint. First, if a complaint occurs, it must be the case

with such nuisance complaints, I assume that the principal changes the decision only if he obtains independent verification.

${ }^{26}$ To see this, note that the principal changes the allocation only if he observes $\alpha_{p}$. (Otherwise he has no information with which to change the decision.) Then the principal only intervenes to change decisions from $x=\alpha_{r} \neq \alpha$ to $x=\alpha_{p}=\alpha$. Note, however that if the agent recommends the customer's preferred action, $\tilde{\alpha}$, the customer has no incentive to complain as the decision can only be changed to one less preferable. Consequently, complaints only arise if (i) $\alpha_{r} \neq \tilde{\alpha}$, and (ii) $\tilde{\alpha}=\alpha$. I assume that the customer does not complain if he is indifferent, as there is some small cost to complaining. Given truth-telling, this occurs with probability $\frac{s(1-q)}{g}$. To see this, note that if $\alpha_{r}=1$ or $\alpha_{r}=-1$, the probability of a complaint conditional on the agent being incorrect is $\frac{1}{2}$, so that the probability of complaint is $\frac{(1-q)}{2}$. On the other hand, if $\alpha_{r}=0$, the conditional probability of a complaint is $\frac{2}{3}$, so the unconditional probability is $\frac{2(1-q)}{3}$. Equally weighting these possibilities yields the probability of a complaint as $\frac{s(1-q)}{9}$. 
that $\alpha_{r} \neq \alpha$, so that the marginal return to observing the correct allocation is 1 . As a result, in any case where the agent complains, the principal will monitor with probability $\rho^{*}\left(\alpha_{\tau}, c\right)=\kappa^{\prime}-1(1)$, where $\rho^{*}\left(\alpha_{r}, m\right)$ is the monitoring intensity when the agent reports $\alpha_{r}$ and the customer sends message $m$.

The calculation is slightly more complicated if no complaint is made. This situation occurs either because the agent "got it right" $\left(\alpha=\alpha_{r}\right)$ or the agent "got it wrong, but the customer does not gain from the change" $\left(\alpha \neq \alpha_{r}\right.$, but $\left.\tilde{\alpha} \neq \alpha\right)$. At the expense of some tedious calculations, I derive the construction of the monitoring propensity to illustrate the relevant issues. To do so, consider what happens when the state where the agent implements no change $\left(\alpha_{r}=0\right)$ and the customer does not complain $(m=n)$. This could be because no change is optimal or because the customer has nothing to gain from the change to the optimum. The principal wants to correct the latter case, so computes its conditional probability. If no complaint is made, the $(\alpha, \beta)$ state belongs to those cases where the agent was right $[\alpha=0]$, or the agent was wrong $[\alpha \neq 0]$, but the consumer does not benefit from the change to $\alpha$, i.e., in states: $[(1,-1),(-1,1)]$. Given the quality of the agent's signal, the first three outcomes imply that the agent was correct (with probability $q$ ) while the final two cases are those where the agent was wrong but $\alpha_{r}=\tilde{\alpha}$, each of which occurs with probability $\left(\frac{1-q}{2}\right)\left(\frac{1}{3}\right)$. The agent's allocation will be corrected in the final two states which occur with conditional probability $\frac{\frac{1-q}{3}}{\frac{1-q}{3}+q}=\frac{1-q}{1+2 q}$. Therefore the principal chooses $\kappa^{\prime}\left(\rho^{*}(0, n)\right)=\left(\frac{1-q}{1+2 q}\right)$ so that

$$
\rho^{*}(0, n)=\kappa^{\prime-1}\left(\frac{1-q}{1+2 q}\right)
$$

By similar analysis, it can easily be shown that

$$
\rho^{*}(1, n)=\rho^{*}(-1, n)=\kappa^{\prime-1}\left(\frac{2(1-q)}{2+q}\right) .
$$

Note that $\rho^{*}\left(\alpha_{r}, n\right)<\rho^{*}\left(\alpha_{r}, c\right)$ and that $\rho^{*}(1, n)=\rho^{*}(-1, n) \geq \rho^{*}(0, n)$ so that in all cases the probability of monitoring increases when the customer makes a complaint.

In this case where complaints are informative and there is no corruption, the surplus from the relationship is

$$
\begin{aligned}
S^{c}=q+\frac{5(1-q)}{9}\left(\rho^{*}\left(\alpha_{r}, c\right)-\kappa\right. & \left(\rho^{*}\left(\alpha_{r}, c\right)\right)+\frac{(1-q)}{9} \sum_{j=-1}^{1} \rho^{*}(j, n) \\
& -\frac{(1+q)}{9}\left[\kappa\left(\rho^{*}(-1, n)\right)+\kappa\left(\rho^{*}(1, n)\right)\right]-\frac{1+2 q}{9} \kappa\left(\rho^{*}(0, n)\right) .
\end{aligned}
$$


By revealed preference, it should be clear that the surplus is higher in the model where complaints are informative than when they are not, as in (4) ${ }^{27}$ In particular, the principal can save on monitoring inefficiencies by intervening more in cases where the agent has likely made a mistake, and avoiding monitoring intensively when there is little chance of the principal changing the decision. Therefore, complaints play an important role in focusing attention to cases where a mistake is likely. This subsection of the paper, therefore, proposes an optimistic view of the role of customer complaints in the monitoring process.

\subsection{The Outcome with Opportunities for Corruption: $v=1$}

Consider the agent's incentives to report honestly when monetary side trades are possible. Remember that the agent is penalized if (i) investigated, and (ii) found to have made an incorrect decision. There is a fundamental tradeoff between these two conditions. First, the agent is more likely to be penalized conditional on monitoring if the agent reports $\alpha_{r} \neq \alpha_{a}$, for the reasons described in the basic model. This effect, not surprisingly, induces more honest reporting by the agent. Second, the agent is more likely to be penalized as the probability of monitoring rises, as the agent can only be penalized if monitored and found to have been incorrect. Thus the agent will have an incentive to carry out actions that reduce the likelihood of monitoring: the precise issue below is to minimize the likelihood of a complaint.

\subsubsection{Is Truth-Telling Possible?}

In order to determine the agent's incentive to report truthfully, consider the incentive of the principal to monitor in various states, assuming truth-telling. It remains the case that the customer complains in the same circumstances as in the previous subsection and that consequently, the principal monitors with probabilities, $\rho^{*}\left(\alpha_{r}, n\right)$ as in (8) and (9), and $\rho^{*}\left(\alpha_{r}, c\right)=\kappa^{\prime-1}(1)$. Because investigations are necessary to penalize the agent, she is more likely to be penalized as the probability of monitoring rises. Then for future reference, note that the increased likelihood of monitoring from a complaint is given by $\kappa^{\prime}-1(1)-\rho^{*}\left(\alpha_{r}, n\right)>0$ for $q<1$. This term is critical in what follows.

Because complaints increase the likelihood of monitoring, the agent may change her actions in order to reduce the prospect of a complaint. But the allocation that she makes has two effects: it affects the likelihood of an investigation and it affects the likelihood of being proved wrong

\footnotetext{
${ }^{27}$ The principal could choose to monitor with probablity $\rho^{*}(1-q)$ in the environment where complaints are informative, but chooses not to do so, as it strictly gets higher surplus from increasing monitoring when there is a greater probability of the agent being incorrect and from reducing it in states where the agent is likely correct.
} 
conditional on an investigation. The incentive of the agent to misrepresent depends on which effect dominates: if the agent is most concerned with avoiding an investigation, her return to being corrupt rises with the penalty, while if monitoring is little affected by the existence of a complaint, the effect of increased penalties is to increase the return to truth-telling, as illustrated in Proposition 2 (see Appendix for a proof).

Proposition 2 The agent can be induced to report truthfully in all states only if

$$
(1-q)\left(\frac{\kappa^{\prime}-1(1)+\kappa^{\prime}-1\left(\frac{2(1-q)}{2+q}\right)}{2}\right) \leq \frac{1+q}{2} \kappa^{\prime-1}\left(\frac{1-q}{1+2 q}\right) .
$$

Thus, investigations cannot be guaranteed to eliminate corruption. It is worth briefly considering the source of this result. There are three effects in operation in (11): (i) the likelihood of a complaint, (ii) the effect of a complaint on monitoring, and (iii) the likelihood of being found wrong in an investigation. First, I show that the agent can reduce the likelihood of a complaint in each of the states where there is a divergence between the social and private optima. Specifically, if she allocates in the socially efficient way, the probability of a complaint is $\frac{1-q}{2}$, while if she offers the customer $\beta$, he never complains.

Then consider the returns to telling the truth when $\alpha_{a}=1$ and $\beta=-1$. (The case where $\alpha_{a}=-1$ and $\beta=1$ is identical.) By doing so, the agent can be penalized only when she is wrong, which occurs with probability $1-q$. Conditional on being wrong, the customer complains half the time so that the agent is penalized with (conditional) probability $\frac{\rho^{*}(1, c)+\rho^{*}(1, n)}{2}$. Therefore the cost of truth-telling is $\Delta(1-q) \frac{\rho^{*}(1, c)+\rho^{*}(1, n)}{2}=\Delta(1-q) \frac{\kappa^{\prime}-1(1)+\kappa^{\prime}-1\left(\frac{2(1-q)}{2+q}\right)}{2}$, the (normalized) LHS of (11). If the agent instead allocates $\beta$, the customer never complains. But she is monitored with probability $\rho^{*}(0, n)=\kappa^{\prime-1}\left(\frac{1-q}{1+2 q}\right)$, and conditional on that, is penalized with probability $q+\frac{1-q}{2}=\frac{1+q}{2}$. (Remember here that she is penalized if monitored and her observation was correct.) Thus the penalty from offering $\beta$ is $\Delta \frac{1+q}{2} \kappa^{\prime-1}\left(\frac{1-q}{1+2 q}\right)$. This yields (11), which is the truth-telling condition for reporting $\alpha_{n}=1$ or $\alpha_{a}=-1$.

An analogous condition arises when the agent should report $\alpha_{r}=0$ but $\beta \neq 0$. This is given by

$$
(1-q)\left(\frac{\kappa^{\prime-1}(1)+\kappa^{\prime}-1\left(\frac{1-q}{1+2 q}\right)}{2}\right) \leq \frac{1+q}{2} \kappa^{\prime-1}\left(\frac{2(1-q)}{2+q}\right) .
$$

This condition is weaker than (11) and so truth-telling in all states arises if (11) holds.

What matters for the ability of the principal to eliminate corruption is how the cost function 
maps into different probabilities of monitoring. If the cost function is flat in the relevant range, there will be little difference in the monitoring probabilities in the various states, and the agent can be induced to allocate honestly. By contrast, if marginal costs are steeply sloped in the relevant range, the principal does not monitor much in the states where no complaints occur, and so corruption is harder to eliminate. ${ }^{28}$

\subsubsection{The Outcome When Corruption Occurs}

If truth-telling is not possible, what is the pure strategy equilibrium of the game (if one exists) where complaints are informative in this way? In the Appendix, I show that when (11) is violated, it is either the case that (i) truth-telling is violated for states $(1,-1)$ and $(-1,1)$ only, or (ii) truth-telling is violated for all states where there is a conflict of interest. In each case, the pure strategy outcome of the game makes intuitive sense. First, when truth-telling is violated for all states where there is a conflict of interest, there is nothing that the principal can do: he chooses $\Delta=0$ and simply allows complete corruption. Second, in some circumstances, (11) is violated but the principal can design a contract such that the agent can be induced to report truthfully when the status quo is optimal. In that case, the principal incurs partial corruption, where it only arises in equilibrium in states $(1,-1)$ and $(-1,1)$. In both cases, corruption arises in equilibrium because of the use of a complaints mechanism. The precise contract offered is given by Proposition 5 in the Appendix. ${ }^{29}$

\subsubsection{Can Incentive Contracts Be Harmful?}

The ability of the principal to deter corruption depends on whether (11) holds or not. But note that (11) is independent of $\Delta$, so that there is no necessary reason to expect that the agent can be deterrred from being corrupt by penalizing on the basis of credible investigations. But even when (11) is violated, this does not imply that the agent should not be offered pay-for-performance

\footnotetext{
${ }^{28}$ For example, consider the case where the cost of monitoring is $\kappa(\epsilon)=0$ for very small $\epsilon>0$ and $\kappa(\rho)=\gamma$ for any $\rho>\epsilon$. (I assume that the principal gets some (very small) probability of identifying the true value of $\alpha$ at no cost because this implies that the principal can induce non-corrupt behavior from the agent in the other states by suitable choice of contract without incurring the cost $\gamma$.) Thus the principal chooses between collecting no signal or incurring the cost $\gamma$ to get a perfect signal. In that case, it should be clear that truth-telling can be guaranteed if $\gamma \leq \frac{1-q}{1+2 q}$; otherwise, corruption occurs in equilibrium, as monitoring is simply not credible.

${ }^{29}$ Note also that I have restricted attention to most efficient equilibrium where the customer reveals information by his complaints. It should be pointed out that this need not necessarily yield higher utility than when complaints are babble. The reason, of course, is that although the principal cannot use complaints to monitor more efficiently ex post, it at least allows the possibility of generating equilibria where the agent is never corrupt. In effect, the principal might prefer to ignore complaints, but cannot do so in this equilibrium. Note also that in many random monitoring settings, it is impossible to find pure strategy equilibria. This is less difficult here because the principal wishes to monitor to correct honest mistakes in addition to reducing corruption.
} 
contracts; it implies only that there are limits to how much can be expected from them. As the model is specified here, with low penalties the agent is always corrupt, ${ }^{30}$ while for high values of $\Delta$, the agent sometimes reports corruptly (only in $\left(\alpha_{a}, \beta\right)$ states $(-1,1)$ and $(1,-1)$ ). Thus this model does not imply that pay-for-performance is harmful per se.

However, even this neutral result is an artifact of the fact that talk is cheap. Consider an alternative where misrepresentation is costly, either because certain information has to be "covered up" or additional supporting information has to be found or because the agent has some inherent honesty. More specifically, consider an ad hoc extension of the model where misrepresenting the truth costs the agent $h$ (for "honesty"). ${ }^{31}$ In the basic model, such preferences for honesty are easily translated into a lower punishment needed for inducing the agent to act honestly (as some of the incentives come for free), a result which is also true if (11) holds. However, if (11) is violated, then the model provides a simple reason why offering pay-for-performance may be harmful. To see this, note that the equivalent condition for truth-telling is given by

$$
(1-q)\left(\frac{\kappa^{\prime}-1(1)+\kappa^{\prime}-1\left(\frac{2(1-q)}{2+q}\right)}{2}\right)-\frac{1+q}{2} \kappa^{\prime-1}\left(\frac{1-q}{1+2 q}\right) \leq \frac{h}{\Delta} .
$$

Consider the case where (11) is violated. High enough honesty costs ( $h \geq \frac{3 q-1}{2}$ is sufficient) will dissuade a bureaucrat from taking bribes in the absence of any incentive contract. But if (11) is violated and $h \geq \frac{3 q-1}{2}$, increases in $\Delta$ (weakly) increase the returns to lying, and there exists some critical $\Delta$ above which the agent lies and below which she implements (to her mind) the social optimum. In other words, the agent finds truth-telling so costly (in the form of higher probabilities of being monitored) that she starts to lie, even though misreporting is costly. To phrase this another way, the costs of having complaints made against her become so great that she starts to lie, despite being predisposed to truth-telling. In this way, using pay for performance can harm incentives, and the optimal contract may offer no incentives. ${ }^{32}$

\footnotetext{
${ }^{30}$ And, so, reports incorrectly in states $(-1,1),(1,-1),(0,-1)$ and $(0,1)$.

${ }^{31}$ There is an alternative interpretation, also mentioned in Tirole (1992), where there are agents who value bribes at $v=1$ and others who value bribes at $\bar{v}$, where $0<\tilde{v}<1$. In that case, if (11) is violated, for low values of $\Delta$ the agent will not accept bribes while for higher levels, he acts in a corrupt fashion.

${ }^{32}$ More specifically, in this extended set-up, if (11) is violated, it is easy to show that the (weakly) optimal $\Delta$ is either 0 (if $h \geq \frac{3 q-1}{2}$ : in which case the innate preferences for honesty, or the costs of misreporting, are large enough to induce truthful reporting in all states) or (weakly) $\Delta \geq \Delta^{* *}$ (if $h<\frac{3 q-1}{2}$, in which case the agent will at least report honestly for all states except $(-1,1)$ and $(1,-1))$; note however, that the optimum may be zero, so that in some circumstances, incentive contracts should be avoided. This result is a little stark, in that it shows that if the agent has a preference for honesty, she may report truthfully with no incentive contract and the first best is feasible. However, it easily generalizes to cases where there is variation in the propensity for agents to be honest, where there is a tradeoff when increasing $\Delta$ between inducing the honest to become dishonest ard inducing the honest to report truthfully.
} 


\subsubsection{Remarks}

- What matters for the results above are that (i) consumers sometimes complain, (ii) complaints increase the likelihood of monitoring, and (iii) the agent would like to avoid being monitored. I have modeled this here by assuming that the consumer gets additional information on the optimal allocation, and complains on the basis of it. It should be stressed that this assumption is not necessary for the results of the paper, and that similar results hold without such a change of opinion. Specifically, consider the case where consumers learn the true state of nature when they contract with the bureaucrat. If the bureaucrat acts corruptly for these individuals, they never complain. This would violate (i) above, so that the informativness of complaints would not arise in equilibrium, as is needed for the results. But now assume that some bureaucrats are honest, and do not report the consumer's preferred allocation. In that case, the consumer will complain about an honest bureaucrat if the he makes the wrong allocation, so that once again complaints will focus investigations. It is straighforward to show that if complaints focus investigations enough (an analog to (11)) in this model, those agents who are predisposed to taking bribes cannot be induced to act honestly by any $\Delta$ in exactly the same way as above. Consequently, the insights above are robust to other modeling choices.

- It is also worth considering the type of decisions that are most likely to be affected by this calculus. By the definition of social inefficiency, someone is harmed by the corrupt decisions of bureaucrats. This section has considered a model where this person cannot complain. In many cases this restriction is unreasonable, because the aggrieved parties know that they have been cheated, and so will complain themselves. But with many assets, it is unclear to the losers that they have been cheated, and their interests may be sufficiently dispersed that no one incurs the costs of trying to have the decision changed. For example, consider the example of a bureaucrat who inefficiently issues passports to unqualified citizens. Society at large loses from this, but society knows little about the details of the case, and even if a citizen knew that corruption has occurred, he may have little incentive to incur the cost of an appeal. Therefore, this model seems better suited to decisions where the aggrieved parties from corruption either are ill-informed or are too disperse to respond.

- The only way to provide incentives here is to monitor in the ex post optimal fashion. As a result, the principal uses complaints to trigger monitoring, and hence increase the likelihood of a penalty, even though these are the states where corruption is least likely! This is why there is an important role in the model for mistakes, because the principal is interested in 
correcting such mistakes, and sometimes the agent gets penalized in the course of correcting honest mistakes. Palmier (1985) notes that bureaucrats seem well aware of this problem: when a Vigilence Commission investigation (in India) is initiated "some mud always sticks" (p.111), illustrating a cost to having the lens focused on a particular case.

To summarize the results of this section, I have attempted to embed the problem of corruption in a real-world mechanism of monitoring: sporadic investigations, which are more likely to occur after a complaint than without one. Using this set-up, I have shown that although complaints can help to focus attention on worthy cases, they also can cause agents to become sufficiently worried about a case being investigated that they simply give the customer what he wants. I believe that this result is important not solely for its theoretical novelty but also because complaints represent the almost ubiquitous mechanism by which corruption investigations are launched, and can easily cause incentive contracting to be ineffectual, despite the optimistic conclusion in Section 2.

\section{Information Choice}

The premise of the previous section has been that agents change their actions in harmful ways when they know that they are being monitored. In this section, I consider another such opportunity, namely, that agents invest in finding out the wrong kind of information as a result of the monitoring system. Underlying this section is the idea that agents typically hold some discretion and qualitative knowledge about their areas of expertise. But they also realise that such information may not be available to the principal, who typically has access to different types of information, such as objective data on revenues, safety reports, bids, etc. One difficulty which then arises is that when agents find their non-verifiable information hard to justify, there is an incentive for them to avoid using discretion and instead to overweight the kinds of information that are also available to the principal.

As a concrete example, consider a case where the agent chooses between two firms bidding for an asset, where the quality of the product offered by the firm is unknown to the pricipal, but on which the agent has private unverifiable information. The socially optimal rule here trades off the benefits of higher quality against lower bids. Yet if information on quality is hard to observe (and mechanisms difficult to write which can credibly reveal it), the agent may be predisposed to accept the highest bid, even in situations where she knows that this is the wrong course of action, as she will likely be punished for following her (non-verifiable) insights. As a result, reward plans which penalize agents for perceived transgressions imply less use of discretion. 
To analyse this case, I consider the following simple adaptation of the benchmark model. First, the information of the principal is imperfect; otherwise, copying the principal's information is costless. I assume that the principal's signal $\alpha_{p}$ is correct with probability $p \geq \frac{1}{3}$, where with probability $\frac{1-p}{2} \leq \frac{1}{3}$, he observes either $\alpha_{p} \neq \alpha$. Furthermore, for simplicity, I assume that collecting $\alpha_{p}$ is costless. ${ }^{33}$

A simple way of modeling the use of agent discretion is to give them choice over the type of information to search for. I allow the agent to choose between two signals, which vary on two dimensions. First, the information has different intrinsic value, in the sense that it better predicts the true social value of the allocation. Second, the information varies in how it correlates with the principal's information. More formally, the agent chooses to collect either of two signals, $\alpha_{a 0}$ or $\alpha_{a 1}$. Information $\alpha_{a i}$ is characterized by two parameters. First, with probability $\mu_{i}$, it produces evidence different from the (costless) signal obtained by the principal, and with complementary probability $\left(1-\mu_{i}\right)$ it replicates the signal of the principal $\alpha_{p}$. In the state where the information is different from that of the principal, the information is correct with probability $q_{i}$. Thus information is characterized by $\left\{q_{i}, \mu_{i}\right\}$ pairs. The agent can collect one and only one piece of information. ${ }^{34}$

Since the information is discrete, either the agent's information will be used or the principal's information will be used. The problem is trivial if the principal's information determines the allocation as there is no reason to provide incentives to the agent. As a result, I restrict attention to cases where the agent's information is used to determine the allocation. First consider the socially optimal information to collect if the agent reports truthfully. The relative value of $\alpha_{a 1}$ over $\alpha_{a 0}$ is

$$
\left[\mu_{1} q_{1}+\left(1-\mu_{1}\right) p\right]-\left[\mu_{0} q_{0}+\left(1-\mu_{0}\right) p\right]
$$

so that the socially optimal allocation is to collect $\alpha_{a 1}$ iff

$$
\mu_{1}\left(q_{1}-p\right) \geq \mu_{0}\left(q_{0}-p\right)
$$

But the agent is rewarded based on investigations, as in (6). As illustrated in Section 2, conditional on information choice, the principal can choose $\Delta$ appropriately such that the agent will use

\footnotetext{
${ }^{33}$ This change makes no difference to the optimistic conclusion in Section 2; with these assumptions, the principal can guarantee truth-telling so long as $\Delta \geq \Delta^{*}$, where $\Delta^{*}=\frac{2}{3 p-1}$.

${ }^{34}$ Giving the agent a binary choice is stark but not important. An alternative continuous model would allow them to collect information on both signals, where the precision of their estimate depends on how much effort she spends on finding out each signal. If collecting information on one signal is a substitute for collecting on the other, the natural analog here would be that she spends excessive efforts on the signal which is more highly correlated with that of the principal.
} 
whatever piece of information she has in a truthful fashion. Specifically, if the agent is known to have collected information $\alpha_{a i}$, the principal can induce the agent to reveal her information truthfully if $\Delta \geq \Delta_{i}^{* *}$, where

$$
\Delta_{i}^{* *}=\frac{\frac{\mu_{i}\left(3 q_{i}-1\right)}{2}+\frac{\left(1-\mu_{i}\right)(3 p-1)}{2}}{\frac{\mu_{i}\left(3 q_{i}-1\right)(3 p-1)}{4}}
$$

Thus, truth telling is not a problem: what is an issue is whether the agent can be induced to collect the right information.

To see the agent's incentives for information collection, simple calculations show that the probability of disagreeing with the principal's information is given by ${ }^{35}$

$$
\mu_{i}\left[\frac{1+p}{2}+\frac{q_{i}(1-3 p)}{2}\right]=d_{i} \geq 0
$$

Since the agent is penalized for an outcome different from that of the principal, what matters for information collection is $\Delta\left(d_{1}-d_{0}\right)$. The agent then chooses information $\alpha_{a 1}$ iff

$$
\left(\mu_{1}-\mu_{0}\right) \frac{1+p}{2}+\frac{\left(\mu_{1} q_{1}-\mu_{0} q_{0}\right)(1-3 p)}{2} \leq 0
$$

It should be obvious how private and social incentives can easily diverge. Note that to maximize surplus, the tradeoff between $\mu_{i}$ and $q_{i}$ is given by totally differentiating $\mu_{1} q_{1}+\left(1-\mu_{1}\right) p$,

$$
\frac{d \mu_{i}}{d q_{i}}=-\frac{q_{i}-p}{\mu_{i}}<0
$$

so that $\mu_{i}$ and $q_{i}$ are substitutes from an efficiency perspective. By contract, the indifference curve for incentive compatability is given by totally differentiating (16),

$$
\frac{d \mu_{i}}{d q_{i}}=-\frac{\mu_{i}\left(\frac{1-3 p}{2}\right)}{\frac{1+p}{2}+\frac{q_{i}(1-3 p)}{2}}>0,
$$

so that in the eyes of the agent, the indifference curve is upward sloped.

The relevant question then becomes whether the principal can choose $\Delta$ such that it gives the agent an incentive both to collect the right type of information and to report truthfully. Specifically, should the principal always offer a contract with $\Delta \geq \Delta_{i}^{* *}$ if the agent collects information $\alpha_{a i}$, as is required for truth-telling? I show below that the answer to this is no, and that sometimes the

${ }^{35}$ This is given by $1-\left(\left(1-\mu_{i}\right)+\mu_{i}\left[p q_{i}+\left(1-q_{i}\right) \frac{(1-p)}{2}\right]\right)$. 
optimal contract may be to offer fewer incentives, knowing that the agent will act corruptly, but at least will collect the correct piece of information. The outcome is given in Proposition 3.

Proposition 3 Without loss of generality let information $\alpha_{1}$ be efficient.

- If $\left(\mu_{1}-\mu_{0}\right) \frac{1+p}{2}+\frac{\left(\mu_{1} q_{1}-\mu_{0} q_{0}\right)(1-3 p)}{2} \geq 0$, then the optimal contract offers $\Delta \geq \Delta_{1}^{* *}$.

- If $\left(\mu_{1}-\mu_{0}\right) \frac{1+p}{2}+\frac{\left(\mu_{1} q_{1}-\mu_{0} q_{0}\right)(1-3 p)}{2}<0$, then the optimal contract offers

$$
\Delta= \begin{cases}\Delta_{0}^{* *} & \text { if } \frac{5}{9}\left[\mu_{1} q_{1}+\left(1-\mu_{1}\right) p\right]+\frac{4}{9}\left[\mu_{1} \frac{1-q_{1}}{2}+\left(1-\mu_{1}\right) \frac{1-p}{2}\right]<\left[\mu_{0} q_{0}+\left(1-\mu_{0}\right) p\right] \\ 0 & \text { otherwise. }\end{cases}
$$

This proposition illustrates the potential costs of offering pay for performance contracts based on the use of independent investigations. First, if the agent collects the correct piece of information when offered the analog to the contract in Section 2, then the incentive constraint to collect the right piece of information does not bind and is irrelevant. In that case the agent is offered an incentive contract where $\Delta \geq \Delta_{1}^{* *}$. This is the first part of the proposition.

However, when the agent collects the wrong piece of information (from (16)) for $\Delta>0$, the principal has two choices. He can either allow the agent to collect the wrong information but induce truth-telling conditional on that, or he can have the agent collect the right information but let him be corrupt by choosing $\Delta=0$. He allows the agent to collect the wrong piece of information if the preferred piece of information $\alpha_{1}$ is not dominant over the less preferred information (if $\left.\frac{5}{9}\left[\mu_{1} q_{1}+\left(1-\mu_{1}\right) p\right]+\frac{4}{9}\left[\mu_{1} \frac{1-q_{1}}{2}+\left(1-\mu_{1}\right) \frac{1-p}{2}\right]<\left[\mu_{0} q_{0}+\left(1-\mu_{0}\right) p\right]\right)$. In this case, the poorly informed but honest agent is better than a more informed corrupt agent. If this condition does not hold, the principal allows corruption but gives the agent no incentive to collect the wrong piece of information. He does this by eliminating the penalties from an investigation so the customer is given what she wants, but at least does so with the correct information set. Since social and private incentives sometimes coincide (with probability $\frac{5}{9}$ ) and the optimal piece of information is much better than the alternative, this is preferred to eliminating corruption at the expense of eliminating discretion. In this case, a better informed but corrupt bureaucrat dominates an honest but poorly informed one.

Again, it is worth taking stock to consider the kinds of examples where this model is relevant. What is important here is that the agent must have some private information about the optimal allocation that is not easily verified by the principal. Examples would be where a regulator has information about the quality of a company's performance or its future investment plans, which should be weighed against, say, a monetary bid for a license, but which are hard to verify by an 
independent commission, which is less well informed. It is less relevant for routine decisions, like the passport example above, where documentation is standard and there is little reason for discretion by the bureaucrat.

\section{The Incentive to Ignore Cases}

So far, I have assumed that there exists a customer who is known to be under investigation by the agent. However, bureaucrats often hold specialized knowledge not only about what actions are appropriate in a given case, but also about which cases should be investigated. For example, bureaucrats are often industry experts who routinely receive information about the necessity for an action, information which is not available to the principal. In such settings, the agent understands that oversight by the principal is unlikely if she does not share her knowledge with him. This gives the bureaucrat and incentive to "look the other way". This section concerns the incentive to notify the principal about cases. If she does not notify the principal, there are however constraints on the allocation that can be offered, since the agent cannot change the allocation from the status quo without informing the principal. The agent now faces an additional incentive: whether to notify the principal, in which case the allocation is ex post optimal for the principal (given his information), or whether to ignore the information that she receives, in which case the allocation received by the customer remains unchanged.

To model this incentive, I assume that there are an infinite number of possible consumers, but that the agent randomly receives a signal on one of them. In the absence of the agent proposing a case, the costs of observing $\alpha_{p}$ are prohibitively high: as a result, the allocation stays unchanged at $x=0 .^{36}$ As in the previous section, I assume that if the agent brings forward a case, the principal observes $\alpha_{p}$, correct with probability $p \geq \frac{1}{3}$, where with probability $\frac{1-p}{2} \leq \frac{1}{3}$, he observes either $\alpha_{p} \neq \alpha$. I assume that collecting $\alpha_{p}$ is costless. As in the last section, it is assumed that the agent's recommendation determines the ultimate allocation.

With no additional complications, this incentive can be easily resolved by rewarding the agent with a bounty whenever she brings a case forward. Putting this in the context of the compensation scheme used in the basic model, the principal can now offer a contract of the following form:

\footnotetext{
${ }^{36}$ The logic for this is simply that there are many dimensions of many customers which the agent could be identifying and finding the right one is akin to "finding a needle in a haystack". Consequently, I make the assumption that in the absence of the agent proposing a case, the principal does not observe $\alpha_{p}$, in which case the allocation remains at its ex ante level, $x=0$.
} 
$w=w_{0}+\Delta_{1} I_{1}-\Delta_{2} I_{2}$, where

$$
I_{1}= \begin{cases}1 & \text { if a case is brought forward } \\ 0 & \text { otherwise }\end{cases}
$$

and

$$
I_{2}= \begin{cases}1 & \text { if the principal observes } \alpha_{p} \neq \alpha_{r} \\ 0 & \text { otherwise }\end{cases}
$$

The principal now needs to design compensation both to induce truth-telling conditional on bringing a case forward, and to induce the agent to bring forward a case. First, I show that the need to induce agents to bring cases forward is not in itself a problem; in effect, the principal can choose $\Delta_{1}$ large enough to do this. But this solution gives rise to an additional problem, because large prizes for bringing cases forward (as is required to induce the agent not to ignore them) give rise to the possibility of "nuisance cases", where agents provide information on cases simply to receive the reward. The incentive to generate such welfare reducing cases then becomes the constraint on inducing the agent not to ignore valuable cases, as I now illustrate.

Assume now that the agent does not receive information about the customer with certainty. Instead, he receives a signal $\alpha_{a}$ on one customer with probability $\phi$ at no cost. In the complementary state of the world (which occurs with probability $1-\phi$ ) the agent receives no free signal but can incur a $\operatorname{cost} N$ to collect a signal $\alpha_{a}^{*}$, which is identically distributed to $\alpha_{a}$; the only difference is that the agent "engineers" a case against the customer by incurring the cost $N$. By natural extension to the previous sections, I assume that the principal's objective function is to maximize surplus (which includes the costs of satisfying the agent's participation constraint). In this section, the expected surplus falls by $N$ from collecting the additional information.

The principal can induce the agent to tell the truth conditional on bringing a case forward by choosing $\Delta_{2}^{*} \geq \frac{2}{3 p-1}$ (see footnote 40 ). Consider the expected value of bringing a case forward. This is given by

$$
\tilde{\Delta}=\Delta_{1}-\Delta_{2} \operatorname{prob}\left(I_{2}=1\right)
$$

which equals

$$
\tilde{\Delta}=\Delta_{1}-\Delta_{2}\left[1-\left(p q+\frac{(1-q)(1-p)}{2}\right)\right]
$$


Then consider the determination of $\tilde{\Delta}$ in the absence of nuisance cases $(N=\infty)$. She has an incentive not to report only in cases where the customer's preferred allocation is 0 and $\beta \neq 0$. In this case, the agent can get a maximum bribe of $q-\frac{1-q}{2}=\frac{3 q-1}{2}$ from ignoring the case. ${ }^{37}$

The principal can then simply choose $\tilde{\Delta}^{*}$ large enough and positive to induce the agent to reveal her information. In particular, he must offer an ex ante expected reward

$$
\tilde{\Delta}^{*} \geq \frac{3 q-1}{2}
$$

to induce her to bring the case forward. If $N$ is large enough, this is the optimal strategy, and so the additional incentive of the agent can be resolved at no cost.

Now consider the incentive to generate inefficient cases. In order to give incentives to bring cases forward the ex ante value of collecting information on the case is given by (at least) $\tilde{\Delta}^{*}$. Then to induce the agent to avoid nuisance cases it must be that $\tilde{\Delta}^{*} \leq N$. i.e.,

$$
\tilde{\Delta}^{*}=\frac{(3 q-1)}{2} \leq N
$$

If $\tilde{\Delta}^{*}<N$, this is the optimal compensation scheme and yields the first best outcome. However, if $\frac{(3 q-1)}{2} \geq N$, the agent cannot be induced to bring all cases forward without also generating nuisance cases. In this case, the principal must choose between a corrupt agent who won't bring some cases forward (ignores cases where the customer wishes for $x=0$ yet it is inefficient to do so) and a truth-telling agent who sometimes generates nuisance cases (incurring costs of $N$ ).

Consider the surplus from collecting nuisance cases. The value of a piece of information is the probability that a piece of information collected by the agent improves the allocation from the status quo of zero, conditional on truth telling (as the agent will always be induced to tell the truth in any equilibrium where the information is collected). This welfare increase is given by

$$
\Sigma=\frac{2}{3}\left(\frac{3 q-1}{2}\right)-N=\left(\frac{3 q-1}{3}\right)-N
$$

Assume that $\Sigma<0$, so that these cases are inefficient. If $\Sigma<0$, it must be the case that (22) is violated and so there is inefficient collection of information whenever the agent tells the truth. ${ }^{38}$

\footnotetext{
${ }^{37}$ To see this, note that with probability $q$, the allocation is correct, while with probability $\frac{1-q}{2}$, the agent erred and recommended $\alpha_{a}+\beta \neq \alpha+\beta$, so the marginal value of the information is $\frac{3 \alpha-1}{2}$.

${ }^{38}$ Obviously, if $\frac{(3 q-1)}{2}>N$, it is always socially efficient to collect the costly information and the principal designs a contract where this occurs by offering $\Delta=\Delta^{* *}$. This case is ignored here by assuming that $\Sigma<0$.
} 


\subsection{Equilibrium}

The remaining issue is to determine how the principal should act in the case where collecting information at $\operatorname{cost} N$ is inefficient $(\Sigma<0)$, but where the agent cannot be induced to bring cases forward where private benefits are for the status quo but the social benefits suggest a change, without also inducing nuisance cases. This occurs when

$$
\frac{(3 q-1)}{2} \geq N>\frac{(3 q-1)}{3}
$$

The principal then has two possibly optimal choices; (i) allow the agent to ignore cases where $\alpha_{a}+\beta=0, \beta \neq 0$, or (ii) induce the agent to report all cases but at the cost of nuisance suits. He chooses the optimal contract based on which option entails the least expected welfare loss, as illustrated in Proposition 4.

Proposition 4 Assume that (23) holds. The equilibrium contract chosen by the principal is

- If $N>\frac{(3 q-1)\left(3-\frac{\phi}{1-\phi}\right)}{9}$ then $\tilde{\Delta}=0, \Delta_{2}=\Delta_{2}^{*}$, and the agent is corrupt when $\tilde{\alpha}_{a}=0, \beta \neq 0$,

- If $N \leq \frac{(3 q-1)\left(3-\frac{\phi}{1-\phi}\right)}{9}$, then $\Delta=\tilde{\Delta}^{*}, \Delta_{2}=\Delta_{2}^{*}$, and the agent reports honestly, but generates "nuisance cases".

This equilibrium outcome is intuitive. On the one hand, if $\phi$ is large, the welfare loss from generating cases is small (as it only occurs with probability $1-\phi$ ), and so the principal allows such nuisance cases and induces the agent to report honestly. In other words, the importance of honesty outweighs the cost of nuisance cases. On the other hand, if $\phi$ is small, the principal prefers to allow corruption rather than incur the large costs of wasted effort. Equally, when the efficiency costs of nuisance cases become small (as $N \rightarrow \frac{3 q-1}{3}$ ), the agent is offered incentives to eliminate corruption, as the cost of generating nuisance suits becomes small. But note that for $\phi$ small, the optimal strategy is to offer no incentives - the central theme of the paper.

\section{Conclusion}

This paper is designed to illustrate influences that can arise in the context of attempts to control corruption through rewards and penalties. Although corruption is a hugely important agency problem, the existing models seem to explain it poorly. This paper has been designed to understand the strengths and limitations of agency contracting when viewed through the lens of an empirically 
important means of monitoring, namely, independent investigations. Although the simplest model offered in Section 2 illustrates how agents can be constrained by suitably designed penalties, this outlook is somewhat optimistic given the adverse behavioral responses by bureaucrats described in the later sections. ${ }^{39}$ I illustrated three harmful behavioral responses to the use of investigations. First, many investigations are (efficiently) instigated by customer complaints. Although such monitoring devices can work in some settings, this can imply that bureaucrats become excessively interested in "keeping the customer happy", even when it is not efficient to do so. In a desire to avoid complaints, I showed that the agent may act in a more corrupt fashion when threatened with large penalties for perceived transgressions. Second, bureaucrats often have private information on how cases should be handled, information which is hard to verify to investigators. I show that when offered incentive contracts, they have an incentive to ignore this information and "do things by the book", offering decisions which are more likely to be consistent with the opinions of their superiors, because acting on information which is likely to be privately held (even though it may be efficient) will be eschewed in order to arrive at outcomes in accord with the official investigation. Finally, bureaucrats sometimes collect bribes to "look the other way". A solution to this is to offer a reward for bringing cases to light. But I illustrate that an implication of this is that the bureaucrat may waste resources by generating nuisance cases simply to receive the bonus. In each of these cases, I show that these distortionary responses may be sufficiently costly that it is more efficient simply to allow corruption. The findings are meant to illustrate why corruption is likely to be a more difficult agency problem to resolve through incentive contracts than others.

It is important to conclude by emphasizing that I am not arguing that investigations should not be used to control corruption. Many investigations of corruption are designed to collect direct evidence of wrongdoing, perhaps by finding evidence of cash being handed over, or bureaucrats living beyond their means. ${ }^{40}$ This type of investigation obviously plays an important role in reducing corruption. But agency theory suggests that contracts can do much more than resolve cases where there is clear ex post evidence of malfeasance. Instead, the contributions of agency theory argue that contracts should be used where the agent is rewarded and penalized for observed measures of performance even without proof of malfeasance. Indeed, in the basis agency model, the agent is never at fault (as the principal knows the effort exerted), yet ex post penalties are necessary. The

\footnotetext{
${ }^{39}$ Closest in spirit to my work is Banerjee (1997) who considers a model of corruption where bureaucrats can be fined for bad decisions, rather like this model. This contract leads to better decision-making, but at the cost of the bureaucrat carrying out inefficient activites to identify appropriate cases. In Banerjee's model, this cost comes in the form of excessive red tape. This result is similar in spirit to those offered here in that incentive contracts for bureaucrats can be harmful because distortionary activities.

${ }^{40} \mathrm{See} \mathrm{Di}$ Tella and Weinschelbaum, 1999, for work on the role of observing the consumption of bureaucrats as a means of controlling corruption.
} 
use of such contracts can do much more than in cases where proof of malfeasance is necessary. The purpose of this paper has been to argue that these contracts are not likely to work so well in the context of bureaucratic corruption, due to the variety of dysfunctional responses that investigations entail. As a result, the effectiveness of controlling corruption through investigations may be limited to cases where proof of malfeasance can be achieved. It is in this sense that agency theory can offer less in the context of bureaucratic corruption than in other settings. 


\section{APPENDIX: Proofs of Results}

\section{Proof of Lemma 1:}

The principal always chooses $\rho(z(j))=\kappa^{\prime-1}(z(j))$. where $z(j)$ is the probability of an error by the agent given a report of $j$. Suppressing $z$, if the principal chooses to monitor with probability $\rho(j)$ when the agent reports $j$, the surplus is trivially given by

$$
S=\sum_{j=-1}^{1} \frac{1}{3}\left([1-\rho(j)]\left[1-\kappa^{\prime}(\rho(j))\right]+\rho(j)-\kappa(\rho(j))\right),
$$

Then consider the computation of the optimal $\rho(j)$. When the agent reports $\alpha_{r}=0$, this is because the agent believes that the $\alpha, \beta$ states are $(0,0),(1,-1)$ or $(-1,1)$. The conditional probability of the state being 0 is $\frac{1}{3}$ and so the probabilility that the allocation needs to be corrected is $\frac{2}{3}$. Hence the principal chooses $p^{*}(0)=\kappa^{\prime-1}\left(\frac{2}{3}\right)$. When the agent reports $\alpha_{r}=1$ (similar calculations apply for reporting -1$)$, this is because the agent believes that the $\alpha, \beta$ states are $(1,0),(1,1)$ or $(0,1)$. The probability of the $\alpha$ state being 1 conditional on this is $\frac{2}{3} q+\left(\frac{1}{3}\right) \frac{1-q}{2}$ and so the probabilility that the allocation needs to be corrected is $q \frac{1}{3}+(1-q)\left(\frac{5}{6}\right)=\frac{5-3 q}{6}$. Hence the principal chooses $\rho^{*}(0)=\kappa^{\prime}-1\left(\frac{5-3 q}{6}\right)$. Substitution yields (1).

\section{Proof of Lemma 2:}

Consider the role of contracts where the agent is rewarded based solely on her allocation. In order to change the agent's allocation from $y$ to $z$, it must be the case that the agent is offered at least a reward of $\frac{3 q-1}{2}$ to do so. To see this note that the private benefits to the consumer from reporting $\tilde{\alpha}_{a}$ rather than $\alpha_{a}$ is $q-\frac{1-q}{2}=\frac{3 q-1}{2}$. If offered a bonus of $w(y)-w(z) \geq \frac{3 q-1}{2}$, the agent will report $y$ rather than $z$ for all states where $\hat{\alpha}_{a}=z$. Then consider the principal's incentives to offer a contract which offers bonuses based on allocations.

Note that they never offer a contract where in equilibrium the agent makes one allocation; in that case, the value of the signal is $\mathbf{0}$, as the agent always makes the same allocation. This offers lower rents than when no contracts are offered. This implies that if there is a contract which dominates no pay-for-performance, which has surplus of $\hat{S}$, it must be the case that the agent makes 2 reports in equilibrium. By symmetry, there are two cases to consider; (i) where the agent reports $\alpha_{r}=-1$ and $\alpha_{r}=1$, and (ii) where the agent reports $\alpha_{r}=-1$ and $\alpha_{r}=0$. (By symmetry the profits from (ii) are the same as when the agent reports $\alpha_{r}=-1$ and $\alpha_{r}=0$.)

Consider the maximum profit possible from (i). This occurs when the principal offers a $w\left(\alpha_{r}\right)$ contract where $w(1)=w(-1) \geq w(0)+\frac{3 q-1}{2}$. As the agent randomizes with equal probability when indifferent, he equally reports -1 and 1 in $\left(\alpha_{a}, \beta\right)$ states $(0,0),(1,-1)$ and $(-1,1)$ and reports $\tilde{\alpha}_{a}$ otherwise. Computation of the relevant conditional probabilities shows that $\rho^{*}(1)=\rho^{*}(-1)=$ $\frac{5(1-q)+4\left(\frac{1+q}{2}\right)}{9}=\frac{7-3 q}{9}$. The ensuing surplus is given by

$$
S_{1}=\left(\left[1-\frac{7-3 q}{9}\right]\left[1-\kappa^{\prime}\left(\frac{7-3 q}{9}\right)\right]+\frac{7-3 q}{9}-\kappa\left(\frac{7-3 q}{9}\right)\right)<\hat{S}
$$

This contract (i) is dominated by allowing the agent to report all three outcomes.

Now consider the maximum profit from (ii). This occurs when the principal offers a $w\left(\alpha_{r}\right)$ contract where $w(-1)=w(0) \geq w(1)+\frac{3 g-1}{2}$. (The case where report -1 is excluded is identical.) As the agent randomizes with equal probability when indifferent, he equally reports 0 and -1 in $\left(\alpha_{a}, \beta\right)$ states $(1,0),(0,1)$ and $(1,1)$ and reports $\tilde{\alpha}_{a}$ otherwise. Computation of the relevant 
conditional probabilities shows that $\rho^{*}(0)=\rho^{*}(-1)=\frac{5(1-q)+4\left(\frac{1+q}{2}\right)}{9}=\frac{13-3 q}{18}$. The ensuing surplus is given by

$$
S_{2}=\left(\left[1-\frac{13-3 q}{18}\right]\left[1-\kappa^{\prime}\left(\frac{13-3 q}{18}\right)\right]+\frac{13-3 q}{18}-\kappa\left(\frac{13-3 q}{18}\right)\right)<\hat{S}
$$

Again, this contract (i) is dominated by allowing the agent to report all three outcomes, so that there is no contract which offers higher utility than $\hat{S}$.

\section{Proof of Proposition 1:}

To illustrate the value of the contract in (6), consider the returns to the agent from truth-telling, $\alpha_{r}=\alpha_{a}$. Then the probability that the agent is wrong is $1-q$. As a result, the probability of monitoring is $\rho^{*}(1-q)=\kappa^{\prime-1}(1-q)$ so that the likelihood of the agent being penalized $\Delta$ is $(1-q) \kappa^{\prime-1}(1-q)$. If (out-of-equilibrium) the agent reports anything other than $\alpha_{r}=\alpha_{a}$, the probability of being penalized is $\frac{1+q}{2} \kappa^{\prime-1}(1-q)$. Taking the difference then yields the marginal return to truth-telling (in probabilities) as

$$
\frac{(3 q-1) \kappa^{\prime}-1(1-q)}{2}
$$

so that the expected increase in the monetary transfer from the principal to the agent from truthtelling is $\frac{\Delta(3 q-1) \kappa^{\prime}-1(1-q)}{2}$. Now consider the maximum bribe that the agent will be offered by the customer. The agent is correct with probability $q \geq \frac{1}{3}$, so that the marginal return to reporting $\tilde{\alpha}_{a}$ rather than anything else is $\left[1-\kappa^{\prime}-1(1-q)\right]\left(q-\frac{1-q}{2}\right)=\left[1-\kappa^{\prime}-1(1-q)\right] \frac{3 q-1}{2} \geq 0$, because with probability $\left[1-\kappa^{\prime-1}(1-q)\right]$ the principal changes the decision. This is the maximum bribe which the agent can extract from the customer; consequently, in order to induce truth telling, the principal can set $\Delta$ such that $\left[1-\kappa^{\prime-1}(1-q)\right] \frac{3 q-1}{2} \leq \kappa^{\prime}-1(1-q) \frac{(3 q-1) \Delta}{2}$. Thus, the principal sets $\Delta \geq \Delta^{*}$, where

$$
\Delta^{*}=\frac{1-\kappa^{\prime}-1(1-q)}{\kappa^{\prime}-1(1-q)} .
$$

\section{Proof of Proposition 2:}

The monitoring probabilities are given by $\rho^{*}(z, m)$ in $(8)$ and (9). Given these probabilities of monitoring, consider the worker's utility from reporting truthfully. Consider the state $\alpha_{a}=0, \beta=1$ (the calculations are identical for $\left.\alpha_{a}=0, \beta=-1\right)$. If the agent tells the truth $\left(\alpha_{\tau}=0\right)$, the customer complains if $\alpha=1$, so that the probability of a complaint is $\frac{1-q}{2}$.

The expected penalty to the agent conditional on a complaint is $\rho^{*}(0, c) \Delta=\kappa^{\prime-1}(1) \Delta$ because the customer only complains is a mistake has been made. The complementary probability of no complaint is $\frac{1+q}{2}$, in which case the probability of monitoring is $\rho^{*}(0, n)=\kappa^{\prime-1}\left(\frac{1-q}{1+2 q}\right)$. The penalty in that state is $\frac{1+q}{2} \kappa^{\prime}-1\left(\frac{1-q}{1+2 q}\right) \frac{1-q}{1+q} \Delta$. Combining these yields the LHS of (12).

Let $U^{*}\left(\alpha_{r} ; \alpha_{a}, \beta\right)$ be the expected utility of the agent from reporting $\alpha_{r}$ after observing $\alpha_{a}$ and $\beta$. Then the expected utility of the agent from reporting $\alpha_{r}=0$ is

$$
U^{*}(0 ; 0,1)=w_{0}-\Delta(1-q)\left(\frac{\kappa^{\prime}-1(1)+\kappa^{\prime}-1\left(\frac{2(1-q)}{2+q}\right)}{2}\right)
$$


By contrast, if the agent reports $\alpha_{r}=1$, the agent never complains. Thus the agent reduces the probability of a complaint by $\frac{1-q}{2}$ by reporting $\tilde{\alpha_{a}}=\beta=1$ rather than $\alpha_{a}=0$. The probabiity of being penalized conditional on an investigation after reporting 1 is $\frac{1+q}{2}$ so that

$$
U^{*}(1 ; 0,1)=w_{0}-\Delta \frac{1+q}{2} \kappa^{\prime-1}\left(\frac{1-q}{1+2 q}\right)+B r i b e,
$$

where Bribe is the transfer from the customer to the agent to report 1 . Not surprisingly, it is simple to show that $U^{*}(-1 ; 0,1) \leq U^{*}(0 ; 0,1)$ so that the choice of the agent is between reporting between $\alpha_{a}=0$ and $\tilde{\alpha}_{a}=\beta=1$.

In order to determine the ability of the principal to eliminate corruption, all that is necessary is to determine whether there exists some value of $\Delta$ for which $U^{*}(0 ; 0,1) \geq U^{*}(1 ; 0,1)$. Trivially comparing these two expressions shows that such a $\Delta$ exists only is (12) holds.

Next consider the likelihood of a complaint in the state $\alpha_{a}=1, \beta=-1$. If the agent tells the truth $\left(\alpha_{r}=1\right)$, the customer complains if $\alpha=-1$, so that the probability of a complaint is $\frac{1-q}{2}$. By contrast, if the agent reports $\alpha_{r}=-1$, the agent never complains. Thus the agent reduces the probability of a complaint by $\frac{1-q}{2}$ by reporting $\beta$ rather than $\alpha_{a}$. Analogous calculations to those above illustrate that the principal can find a $\Delta$ to induce truth-telling only if (11) holds.

\section{Proof of Proposition 3:}

First consider the contract which is required to induce truth telling, conditional on information $\alpha_{a i}$ being collected. The probability that the principal's observation is different from the agent's is $\frac{\mu_{i}\left(3 q_{i}-1\right)(3 p-1)}{4}$ and the expected monetary penalty is $\frac{\Delta \mu_{i}\left(3 q_{i}-1\right)(3 p-1)}{4}$. The maximum bribe that the agent can receive from the customer is given by $\frac{\mu_{i}\left(3 q_{i}-1\right)}{2}+\frac{\left(1-\mu_{i}\right)(3 p-1)}{2}$. Therefore, by offering $\Delta \geq \Delta^{* *}$, where

$$
\Delta^{* *}=\frac{\frac{\mu_{i}\left(3 q_{i}-1\right)}{2}+\frac{\left(1-\mu_{i}\right)(3 p-1)}{2}}{\frac{\mu_{i}\left(3 q_{i}-1\right)(3 p-1)}{4}},
$$

the agent can be induced to report information truthfully, conditional on her information choice.

Second, consider the incentive of the agent to collect information. As illustrated in the text, when $c=0$, the agent will collect the efficient piece of information $\alpha_{1}$ only if

$$
\left(\mu_{1}-\mu_{0}\right) \frac{1+p}{2}+\frac{\left(\mu_{1} q_{1}-\mu_{0} q_{0}\right)(1-3 p)}{2} \leq 0
$$

for any $\Delta>0$. If $\Delta=0$, the agent collects the efficient piece of information, as she is indifferent. The principal's choice is then (i) choose $\Delta=0$, in which case the agent collects the correct piece of information but reports $\tilde{\alpha}_{a 1}$ or (ii) choose $\Delta \geq \Delta^{* *}$, in which case the agent collects the incorrect piece of information $\alpha_{a 0}$ and reports truthfully. Straighforward calculations show that the principal prefers (i) whenever $\frac{5}{9}\left[\mu_{1} q_{1}+\left(1-\mu_{1}\right) p\right]+\frac{4}{9}\left[\mu_{1} \frac{1-q_{1}}{2}+\left(1-\mu_{1}\right) \frac{1-p}{2}\right]<\left[\mu_{0} q_{0}+\left(1-\mu_{0}\right) p\right]$ and (ii) otherwise.

\section{Proof of Proposition 4:}

The welfare loss from (i) allowing the agent to ignore cases is $\frac{2 \phi}{9} \frac{(3 q-1)}{2}$ because the agent does not use her free information in the $\left(\alpha_{a}, \beta\right)$ states $(1,-1)$ and $(-1,1)$, which occurs with probability $\frac{2 \phi}{9}$, and the welfare loss from not using the information in that state is $\frac{(3 q-1)}{2}$. On the other hand, if the agent collects the information (which occurs with probability $1-\phi$ ), the the welfare loss 
is $(1-\phi)\left[\frac{3 q-1}{3}-N\right]$. Thus the principal will allow the agent to ignore cases in equilibrium, so corruption occurs if $\frac{2 \phi}{9} \frac{(3 q-1)}{2}<(1-\phi)\left[\frac{3 q-1}{3}-N\right]$, or after rearranging if

$$
N>\frac{(3 q-1)\left(3-\frac{\phi}{1-\phi}\right)}{9}
$$

Otherwise the agent generates nuisance cases in equilibrium, as this is a necessary cost of inducing the agent to bring cases forward.

Proposition 5 When (11) is violated, the optimal pure strategy equilibrium (if one exists) where complaints are informative is:

1. If $(1-q)\left(\frac{\kappa^{\prime}-1(1)+\kappa^{\prime}-1\left(\frac{1-q}{2}\right)}{2}\right) \leq \frac{1+q}{2} \kappa^{\prime}-1\left(\frac{2}{5}\right)$, then:

- Allocations: The agent allocates $\alpha_{a}$ except where $\alpha_{a}=-1, \beta=1$ or $\alpha_{a}=1, \beta=-1$, in which case she implements $\beta$.

- Monitoring: The principal chooses $\rho^{* *}\left(\alpha_{r}, c\right)=\kappa^{\prime}-1(1), \rho^{* *}(0, n)=\kappa^{\prime-1}\left(\frac{2}{5}\right)$ and $\rho^{* *}(1, n)=$ $\rho^{* *}(-1, n)=\kappa^{\prime}-1\left(\frac{1-q}{2}\right)$.

- Complaints: The customer complains if his preferred allocation is the social optimum but is not recommended by the agent.

- Contracts: $\Delta \geq \Delta^{* *}$, where $\Delta^{* *}=\frac{\frac{1+q}{2}\left(1-\rho^{* *}(1, n)\right)}{(1-q)\left(\frac{e^{* *}(0,0)+\rho^{* *}(0, n)}{2}\right)-\frac{1+q}{2} p^{* *}(1, n)}$.

2. If $(1-q)\left(\frac{\kappa^{\prime}-1(1)+\kappa^{\prime}-1\left(\frac{1-q}{2}\right)}{2}\right)>\frac{1+q}{2} \kappa^{\prime}-1\left(\frac{2}{5}\right)$ :

- Allocations: The agent always implements $\beta$ when $\beta \neq 0$, and $\alpha_{a}$ otherwise.

- Complaints: The customer complains if his preferred allocation is the social optimum but is not recommended by the agent.

- Contracts: $\Delta=0$.

Proof:

1. Consider a possible pure strategy equilibrium where the principal cannot induce the agent to report the state truthfully when $\alpha_{a}=-1, \beta=1$ or $\alpha_{a}=1, \beta=-1$. Can the principal choose a penalty $\Delta$ to eliminate corruption in the other states? Consider the case where $\alpha_{a}=0, \beta=1$ (the case where $\alpha_{a}=0, \beta=-1$ is identical). The customer complaints in the usual way. As a result, the principal monitors as follows.

If the customer complains, the agent is surely incorrect and so the principal chooses $\rho^{* *}\left(\alpha_{r}, c\right)=$ $\kappa^{\prime}-1(1)$. Next, if the agent reports $\alpha_{r}=0$ and there is no complaint, this implies that $(\alpha, \beta)$ belongs to $(-1,1),(0,1),(0,-1),(0,0)$ and $(1,-1)$. The principal will correct the decision only if the states are $(-1,1)$ or $(1,-1)$. The conditional likelihood that the state is either $(-1,1)$ or $(1,-1)$, given that it belongs to $(-1,1),(0,1),(0,-1),(0,0)$ or $(1,-1)$, is simply computed to be $\frac{2}{5}$. Hence the principal chooses $\rho^{* *}(0, n)=\kappa^{\prime}-1\left(\frac{2}{5}\right)$. Now consider the case in this equilibrium if the agent reports 1 (or -1 ) and there is no complaint. The agent reports $\alpha_{r}=1$ in states $(1,0)$ and $(1,1)$. In the former case, the customer always complains if the agent was wrong. Thus, conditional on no complaint, there is a zero probability of being wrong. In the latter, he never complains, so the 
the probability of being incorrect is $(1-q)$. Equally weighting these options (as the distributions are uniform) shows that the probability of the agent being wrong conditional on no complaint is $\frac{1-q}{2}$ and so $\rho^{* *}(1, n)=\rho^{* *}(-1, n)=\kappa^{\prime}-1\left(\frac{1-q}{2}\right)$.

The agent's incentive to report truthfully then depends on exactly the same calculation as (12), but with monitoring propensities as above. This yields that if $(1-q)\left(\frac{\kappa^{\prime}-1(1)+\kappa^{\prime}-1\left(\frac{(1-q)}{2}\right)}{2}\right) \leq$ $\frac{1+q}{2} \kappa^{\prime-1}\left(\frac{2}{5}\right)$, the agent can be offered a penalty large enough to reports truthfully with the equiibrium strategies.

All that remains then is to derive the penalty necessary to induce truth-telling. First consider the agent's utility from truthful reporting. Her utility is

$$
U(0 ; 0,1)=w_{0}-\frac{1-q}{2} \rho^{* *}(0, c) \Delta-\frac{1-q}{2} \rho^{* *}(0, n) \Delta .
$$

If the agent reports $\alpha_{r}=\tilde{\alpha}_{a}=1$, her utility is

$$
U(1 ; 0,1)=w_{0}-\frac{1+q}{2} \rho^{* *}(1, n) \Delta+\text { Bribe. }
$$

The maximum bribe that the customer will pay the agent to report 1 is $\frac{1+q}{2}\left(1-\rho^{* *}(1, n)\right)$, because the customer values the allocation if (i) it is not investgated and (ii) either $\alpha=1$ or $\alpha=0$, which occurs with probability $\frac{1+q}{2}$. Therefore the principal can deter misreporting by choosing $\Delta$ such that

$$
(1-q)\left(\frac{\rho^{* *}(0, c)+\rho^{* *}(0, n)}{2}\right)-\frac{1+q}{2} \rho^{* *}(1, n) \geq \frac{\frac{1+q}{2}\left(1-\rho^{* *}(1, n)\right)}{\Delta} .
$$

Straightforward manipulation yields $\Delta^{* *}$ above.

2. When $(1-q)\left(\frac{\kappa^{\prime}-1(1)+\kappa^{\prime}-1\left(\frac{(1-q)}{2}\right)}{2}\right)>\frac{1+q}{2} \kappa^{\prime-1}\left(\frac{2}{5}\right)$, the principal cannot induce the agent to report the state truthfully in any pure strategy equilibrium where there is a divergence between social and private optima. This implies that in any pure strategy, the allocation is idependent of $\Delta$ so the principal (weakly) chooses $\Delta=0$. In the case where $\alpha_{a}=-1, \beta=1$ or $\alpha_{a}=1, \beta=-1$, this implies that the allocation is $\tilde{\alpha}_{a}$ for $\Delta$ low and $\beta$ for $\Delta$ high. The expected surplus is identical in both cases, but the monetary transfer to the agent is higher when $\tilde{\alpha}_{a}$ is reported, which can be extraced from the agent in the ex ante contract, and hence is preferred to reporting $\beta$. Hence, the (weakly) optimal contract offers $\Delta=0$. 


\section{REFERENCES}

Alam, M.S., "Some Economic Costs of Corruption in LDCs," Journal of Development Studies, $1992,89-97$.

Banerjee, Abhijit, "A Theory of Misgovernance," Quarterly Journal of Economics, November 1997, Vol. 107(4), 1289-1332.

Basu, Kaushik, Sudipto Bhattacharya and Ajit Mishra, "Notes on Bribery and the Control of Corruption," Journal of Public Economics, 1992, Vol. 48, 349-59.

Becker, G., , "Crime and Punishment: An Economic Approach." Journal of Political Economy, 1968, Vol. 76, pp. 169-217.

Besley, Tim and John McLaren, "Taxes and Bribery: The Role of Wage Incentives," Economic Journal, January 1993, Vol. 103, 119-41.

Bardhan, Pranab, "Corruption and Development: A Review of Issues," Journal of Economic Literature, September 1997, Vol. 35, 1320-46.

Braun, Miguel, and Rafael DiTella, "Inflation and Corruption," mimeo, Harvard Business School, 2000.

Chung, Kim-Sau, "Inducing Optimal Information Collection," mimeo, Northwestern University, 1999.

Di Tella, Rafael, and Federico Weinschelbaum "To Catch a Thief: Wealth as a Corruption Controlling Device," mimeo, Harvard Business School, 1999.

Eskeland, Gunnar, and Henrik Thiele, "Corruption Under Moral Hazard," mimeo, World Bank, 1999.

Flatters, Frank and Bentley MacLeod, "Administrative Corruption and Taxation," International Tax and Public Finance, 1995, Vol. 109, 1125-1156.

Gibbons, Robert and Michael Waldman, "Careers in Organizations: Theory and Evidence", forthcoming, Handbook of Labor Economics.

Holmstrom, Bengt, "Moral Hazard and Observability", Bell Journal of Economics, 1979, 10, $74-91$.

Holmstrom, Bengt and Paul Milgrom, "Multi-Task Principal Agent Analyses: Linear Contracts, Asset Ownership and Job Design", Journal of Law, Economics, and Organization, $1992,7,24-52$.

Jost, Peter-Jurgen, "Monitoring in Principal-Agent Relationships," Journal of Institutional and Theoretical Economics, 1991, Vol. 147, 517-38.

Khalil, Fahad, "Auditing Without Commitment," RAND Journal of Economics, 1997, 28(4), $629-40$.

Klittgard, Robert, Controlling Corrpution, University of California Press, 1994, Los Angeles.

Leff, Nathaniel, "Economic Development through Bureaucratic Corruption," The American Behavioral Scientist, 1664, 8(2), 8-14. 
Mauro, Paolo, "Corruption and Growth," Quarterly Journal of Economics, August 1995, Vol. $2,397-417$.

Mitusch, Kay, "Subjective Evaluation and Information Efficiency in Organizations," November 1998, Freie Universitat Berlin.

Mookherjee, Dilip and I.P.L. Png, "Corruptible Law Enforcers: How Should They Be Compensated," Economic Journal, January 1995, Vol. 105, 145-59.

Palmier, Leslie, The Control of Bureaucratic Corruption: Case Studies in Asia, Allied Publishers, 1985, New Dehli.

Prendergast, Canice, "The Provision of Incentives in Firms", Journal of Economic Literature, 1999, 37, 7-63.

Prendergast, Canice, "What Trade-off of Risk and Incentives", American Economic Review Papers and Proceedings, 2000a, May, 421-25.

Prendergast, Canice, "The Tenuous Trade-Off Between Risk and Incentives?", mimeo, University of Chicago, 2000b.

Rose-Ackerman, Susan, "When Is Corruption Harmful?," working paper, World Bank, 1996.

Tirole, Jean, "Hierarchies and Bureaucracies: On the Role of Collusion in Organizations", Journal of Law, Economics and Organizations, 1986, 2:2, 181-214.

Tirole, Jean (1992), "Collusion and the Theory of Organizations", in Advances in Economic Theory: Sixth World Congress, Vol. 2. J. Laffont, ed. Cambridge: Cambridge University Press.

Wade, Robert, "The Market For Public Office: Why the Indian State is Not Better at Development," World Development, April 1985, Vol. 13(4), 467-97.

Wei, Shang-Jin, "Why is Corruption So Much More Taxing Than Tax?," mimeo, Harvard University, June 1997. 



\section{Policy Research Working Paper Series}

Title

WPS2480 Productivity Growth and Resource Degradation in Pakistan's Punjab:

A Decomposition Analysis

WPS2481 Foreign Direct Investment in Africa: Policies Also Matter

WPS2482 Can Institutions Resolve Ethnic Conflict?

WPS2483 The Credit Crunch in East Asia: What Can Bank Excess Liquid Assets Tell Us?

WPS2484 Banking Crises in Transition Economies: Fiscal Costs and Related Issues

WPS2485 Are Corruption and Taxation Really Harmful to Growth? Firm-Level Evidence

WPS2486 Who Must Pay Bribes and How Much? Jakob Svensson Evidence from a Cross-Section of Firms

WPS2487 Finance and Macroeconomic Volatility Cevdet Denizer

WPS2488 Revisiting the Link between Poverty and Child Labor: The Ghanaian Experience

WPS2489 Banking Crises and Exchange Rate Regimes: Is There a Link?

WPS2490 Contractual Savings, Stock, and Asset Markets

WPS2491 Labor Demand and Trade Reform in Latin America

WPS2492 Health Insurance Reform in Four Latin American Countries: Theory and Practice Murat F. lyigun

Ann L. Owen

Date

Contact for paper

Mubarik Ali

Derek Byerlee

November 2000

D. Byerlee

87287

Jacques Morisset

William Easterly

Pierre-Richard Agénor Joshua Aizenman

Alexander Hoffmaister

Helena Tang

Edda Zoli

Irina Klytchnikova

Raymond Fisman

Jakob Svensson

Niels-Hugo Blunch

Dorte Verner

Ilker Domaç

Maria Soledad Martinez Peria

Gregorio Impavido

Alberto R. Musalem

Pablo Fajnzylber

William F. Maloney

William Jack
November 2000

November 2000

November 2000

November 2000

November 2000

November 2000

November 2000

November 2000

November 2000

November 2000

November 2000
H. Vargas

37871

A. Carcani 30241

N. Busjeet 33997

K. Labrie 31001

M. Gosiengfiao 33363

A. Carcani 30241

R. Bonfield 31248

R. Bonfield 31248

1. Partola 35759

P. Braxton 32720

T. Gomez 32127

H. Sladovich 37698 
Policy Research Working Paper Series

Title

WPS2493 Annuity Markets in Comparative Perspective: Do Consumers Get Their Money's Worth?

WPS2494 The Relevance of Index Funds for Pension Investment in Equities

WPS2495 The Australian Annuity Market

WPS2496 Perspectives on the Sources of Heterogeneity in Indian Industry

WPS2497 State Policies and Women's Autonomy in China, India, and the Republic of Korea, 1950-2000: Lessons from Contrasting Experiences

WPS2498 Sustaining Economic Welfare: Estimating Changes in Per Capita Wealth

WPS2499 The Treatment of Non-Essential Inputs in a Cobb-Douglas Technology: An Application to Mexican Rural Household-Level Data
Author

Estelle James

Dimitri Vittas

Ajay Shah

Kshama Fernandes

David M. Knox

Somik V. Lall

G. Chris Rodrigo

Monica Das Gupta

Sunhwa Lee

Patricia Uberoi

Danning Wang

Lihong Wang

Xiaodan Zhang

Kirk Hamilton

Isidro Soloaga
Date

November 2000

Contact for paper

A. Yaptenco 31823

November 2000

A. Yaptenco 31823

November 2000

A. Yaptenco 31823

November 2000

R. Yazigi 37176

November 2000

M. Das Gupta 31983

November 2000

L. Pivera

82819

December 2000
L. Tabada 36896 